\title{
A scoping review of research on play-based pedagogies in kindergarten education
}

\author{
Angela Pyle ${ }^{\mathrm{a}}$, Christopher DeLuca ${ }^{\mathrm{b}}$, \& Erica Danniels ${ }^{\mathrm{a}}$ \\ a Ontario Institute for the Study of Education, University of Toronto, Canada \\ ${ }^{b}$ Faculty of Education, Queen's University, Kingston, Canada
}

Full Citation:

Pyle, A., De Luca, C., \& Danniels, E. (2017). A scoping review of research on play-based pedagogies in kindergarten education. Review of Education, 5(3), 311-351.
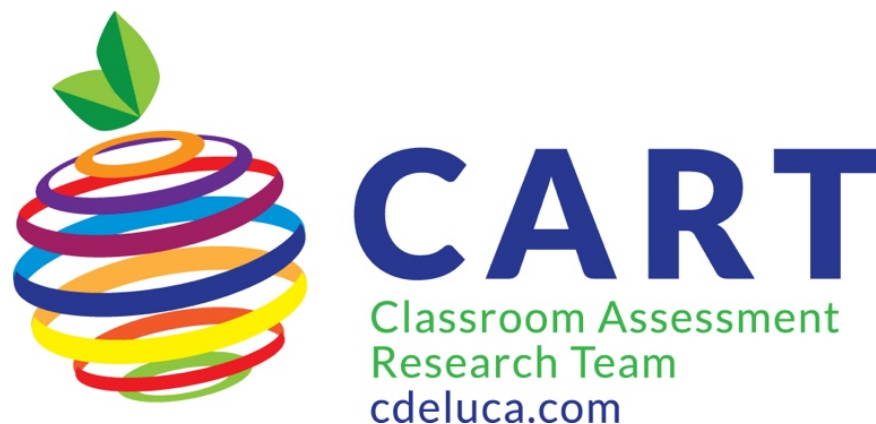

Classroom Assessment Research Team cdeluca.com

\author{
Contact: \\ Christopher DeLuca \\ cdeluca@queensu.ca \\ @ChrisDeLuca20
}




\begin{abstract}
Across a number of countries, play-based learning is the current mandated pedagogy in early years curricula. However, a lack of consensus remains both in research and practice regarding the value and role of play in children's learning. This scoping review analyzes 168 articles addressing play-based learning for 4-5 year old children divided into three categories: research on play for developmental learning, research on play for academic learning, and factors influencing play in kindergarten classrooms. Much of the research endorsed play as fulfilling an important role in early learning. However, two disparate perspectives concerning the role of play for developmental versus academic learning demonstrate different orientations towards the value and potential benefits of play. Research focused on developmental learning endorsed the use of free play and a passive teacher role, while research focused on academic learning endorsed teacher-directed and mutually directed play where the teacher fulfills an active play role. A similar lack of consensus was found among research with educators regarding the role and benefits of play. These findings indicate a need to move away from the current binary stance regarding play and towards an integration of perspectives and practices, with different types of play perceived as complementary rather than incompatible.
\end{abstract}

Keywords: kindergarten, early years, play, learning, teacher practice 


\section{A Scoping Review of Research on Play-based Pedagogies in Kindergarten Education}

Kindergarten education has been the focus of significant curricular change in recent years across educational systems in Canada, the UK and elsewhere (e.g., Gananathan, 2011; Ling-Yin, 2006; Pan \& Li, 2012). Most notably, current curricular reforms have increased academic standards for young learners and have mandated a play-based pedagogical approach across contexts (OME, 2011; Synodi, 2010). However, despite this swift reform, there remains a lack of consensus on the value and role of play in learning (e.g., Baker, 2014a; Vong, 2012).

Accordingly, the purpose of this scoping review is to systematically examine the empirical and theoretical research related to play-based pedagogies and their effectiveness on early student learning.

Across the extant literature, the proposed benefits of play tend to be examined through the lens of two different perspectives: developmental learning (e.g., Ghafouri \& Wien, 2005) and academic learning (e.g., Kotsopoulos, Makosz, Zambrzycka, \& McCarthy, 2015). These two perspectives differ significantly with respect to the type of play endorsed and the recommended role of the teacher. Among teachers and other educational providers, research has revealed differing beliefs regarding the relationship between play and learning (e.g., Fung \& Cheng, 2012), gaps between reported beliefs and observed classroom practices (e.g., Foote, Smith, \& Ellis, 2004), and a number of reported barriers to implementing play-based learning in kindergarten (e.g., Hu, Fuentes, Wang, \& Ye, 2014).

Given current kindergarten reforms around the world to promote academic learning through play, there is an urgent need to synthesize existing literature on the value and role of play in kindergarten education. This scoping literature review examines peer-reviewed studies of 
play-based kindergarten education in order to highlight consistent findings, incongruences, and gaps in the play-based learning literature, concluding with recommendations for research and practice.

\section{Current Context of Play-based Kindergarten Education}

In recent years, a shift towards the promotion of learning through play in kindergarten has taken place in countries such as Canada (Lynch, 2014), China (Pan \& Li, 2012), United Arab Emirates (Baker, 2014a), Britain (Tafa, 2008), New Zealand (Synodi, 2010), Japan (Hegde, Sugita, Crane-Mitchell, \& Averett, 2014), Greece (Tafa, 2008), Singapore (Ling-Yin, 2006), and South Korea (Kim 2004). At the same time, in many of these countries there is a strong push for high quality academic learning in the early years in order to prepare children for subsequent schooling (e.g., Baker, 2014a; Li, 2004). This academic push has been influenced by a number of factors, including prescribed curricular standards (e.g., Baker, 2014b), parental expectations (e.g., Fung, 2009), as well as cultural beliefs and practices (e.g., Ling-Yin, 2006). This dual emphasis on academic standards and learning through play has led to reported tensions from educators struggling to integrate the concepts of learning and play (Hegde \& Cassidy, 2009; Lynch, 2014). Historically, research indicates that kindergarten educators separated play-based learning from academics (Pramling Samuelsson \& Johansson, 2006); however, current mandates require teachers to shift their perspective towards teaching academic learning through play (e.g., Wallerstedt \& Pramling, 2012).

Given the required shift in beliefs about play and learning, recent qualitative research into early childhood education has turned its attention to teachers' beliefs, practices, and barriers with play-based learning pedagogies (e.g., Pui-Wah \& Stimpson, 2004). Although current curricula highlight the importance of using play-based learning practices, descriptions of the role of play 
in learning in these curricula have been varied (Synodi, 2010). For example, play has been highlighted as important for some areas of learning in Norway and New Zealand but not others, while play in Japan's curriculum play has been emphasized as important for social-emotional development but not for academic learning (Synodi, 2010). In addition to these varied interpretations at the curricular level, researchers have discovered that the implementation of play-based learning practices has been far from straightforward for educators. Despite the geographic diversity across studies, a number of similarities have been uncovered, including difficulties integrating the concepts of play and learning (e.g., Vong, 2012), discrepancies between reported beliefs and observed teaching practices (e.g., Foote et al., 2004), and practical challenges in implementing play-based learning strategies within today's classrooms (e.g., Cooney, 2004). Highlighted across research studies, the shift towards play-based learning both conceptually and practically has been met with some concerns and barriers.

\section{Defining Play and Types of Play in Kindergarten Education}

Although the exact definition of play has been the subject of debate among researchers (Wallerstedt \& Pramling, 2012), two distinct types of play are often described and examined in the literature: free or child-directed play (e.g., Fleer, 2011b) and teacher-directed play (e.g., Newbury, Wooldridge, Peet, \& Bertelsen, 2015). In free play, children have the opportunity to engage in a variety of play activities freely chosen and directed by themselves without active guidance from teachers (Weisberg, Hirsh-Pasek, \& Golinkoff, 2013; Wood \& Attfield, 2005). On the other hand, teacher-directed play has been used to refer to intentionally planned games and play activities by teachers for their students to be used as learning opportunities, where students follow specified rules of play as outlined by teachers (Gmitrova, Podhajecká, \& Gmitrov, 2009; Newbury et al., 2015). Between these two types of play, researchers have 
referenced a third type of play that is directed by both students and teachers, sometimes referred to as mutually directed play (e.g., Henry, 1990; Synodi, 2010). Much of the research discusses the importance of teachers intervening during children's play to capitalize on potential learning opportunities by getting involved in the play rather than disrupting or transforming student play (i.e., mutually directed play) (e.g., Hope-Southcott, 2013; McLennan, 2012; Wood \& Attfield, 2005). These different types of play are defined by who has control over the play activity (i.e., student or teacher), rather than by the nature of the activity. Therefore, all three categories can include play with toys (i.e., playing with blocks, figures, or other objects) that can be explored or manipulated (e.g., Hansel, 2015), and dramatic or pretend play (i.e., play activities that involve the transformation of objects or actions in a symbolic manner which can involve role taking, negotiation, and improvisation with or without objects) (Gmitrová \& Gmitrov, 2004). Researchers have endorsed all three types of play (teacher-directed, mutually directed, and free play) as beneficial learning strategies for children, however the endorsements of specific types of play tend to vary depending on the type of learning in question.

\section{The Role of Play in Learning}

Current research that examines the role of play in learning tends to be split depending on whether the focus is on developmental learning (e.g., Bodrova \& Leong, 2003) or academic learning (e.g., Ihmeideh, 2015). Researchers focused on the role of play in developmental learning emphasize the overall development of the child, including social-emotional development (e.g., Tal, Fares, Azmi, \& Waab, 2008), general cognitive development (e.g., Hansel, 2015), and self-regulation (e.g., Bodrova \& Leong, 2008). Researchers focused on play and developmental learning in kindergarten propose that a focus on teaching discrete academic knowledge and skills in the classroom is too narrow, since other areas of development should 
also be given priority to encourage positive growth and well-being (Tal et al., 2008). Many researchers have highlighted concerns that an increased focus on academic standards are resulting in a decrease in playtime and a potential increase in direct instruction, a strategy which may not be developmentally appropriate or optimal for developmental learning (Bowden, 2015; Miller, 2005; L. Wood, 2014). Playtime is frequently conceptualized as a time for child-directed free play, which is proposed to be beneficial for multiple areas of development (e.g., Fredrikson, 2012; Ghafouri \& Wien, 2005). The role of teachers during periods of play has been described as passive and observant (Andrews, 2015), an enabler of free exploration (L. Wood, 2014), and someone who offers ideas to extend learning when appropriate (Bottini \& Grossman, 2005).

Researchers focused on the role of play in academic learning examine the relatively narrower scope of how play activities can impact the learning of prescribed academic skills, and address the topics of general academic learning (e.g., Riek, 2014), early math skills (e.g., Presser, Clements, Ginsburg, \& Ertle, 2015), and literacy skills, including oral language skills (e.g., Elvin, Maagerø, \& Simonsen, 2007) as well as reading and writing (e.g., Wohlwend, 2008). Many researchers focused on examining play and academic learning argue in favour of teaching prescribed academic goals in kindergarten in a playful manner that is more engaging and developmentally appropriate than didactic teaching strategies (e.g., Balfanz, 2003; Sarama \& Clements, 2006). A wide scope of different activities is considered by these researchers to be in the realm of play, including types of teacher-directed play (e.g., Isom, 2014), mutually directed play (e.g., Sarama \& Clements, 2006), and free play in enriched environments (e.g., Yoon, 2014). In this area of research, teachers are described as taking active roles in play to facilitate learning, including setting up the environment (e.g., Korat, Bahar, \& Snapir, 2002), leading specially designed games or activities (e.g., Presser et al., 2015), and intervening in child- 
directed play to incorporate academic learning (e.g., Sarama \& Clements, 2006). Adult guidance in play is often highlighted as a critical component in order for children in kindergarten to reach their full academic potential, above and beyond free play alone (e.g., Balfanz, 2003). As a result of these differing perspectives regarding the optimal role of play in learning, two different areas of research have developed over the years with a lack of attention paid to the overall scope of research on play-based learning, the integration of different perspectives, and the effectiveness of diverse types of play for early student learning.

\section{Method}

This research employed a scoping review methodology (Arksey \& O’Malley, 2005) to analyze research on play-based pedagogies and their effectiveness for early student learning. This methodology follows five framework stages which will be discussed in turn: (a) identifying the research question, (b) identifying relevant studies, (c) study selection, (d) charting the data, and (e) summarizing and reporting the results (Arksey \& O’Malley, 2005).

\section{Scoping Review Research Question}

The research question served as the starting point for delineating the parameters of the study, and concepts contained in the research question will be defined in order to clarify the focus of the study (Arksey \& O’Malley, 2005). Our preliminary guiding research question was:

"What does the extant literature tell us about the scope of research done on play-based pedagogies with kindergarten-aged students (4-5 year olds)?" The general concept of 'play-based pedagogies' guided the research in order to encompass a broad definition of play, allowing articles focused on teacher-directed play, child-directed play, and/or mutually directed play to be included. The focus of this review was on 4-5 year old students, encompassing students in both kindergarten and other early educational programs serving the same age group (e.g., Gray \& 
Ryan, 2016). Following the recommendations from Arksey and O'Malley (2005), a wide approach to the search criteria was followed in order to capture the breadth of research in this area of study, and decisions on how to set parameters on the retrieved articles were made once the general volume and scope of the literature was examined.

\section{Identification of Relevant Studies}

Relevant keyword searches were conducted from the Education Source (EBSCOhost) electronic database. This database was selected because it offers the largest and most complete collection of international full-text education journals in the world (Concordia University Library, No Date). Articles from the years 2000-2016 were chosen since the shift towards playbased learning in early years curricula occurred during this time frame across a number of countries (e.g., Hunter \& Walsh, 2014; Lynch, 2014; Martlew, Stephen, \& Ellis, 2011), and time span decisions are often necessary from a practical standpoint in scoping literature reviews (Arksey \& O’Malley, 2005). The search terms used for this review were "play-based learning + (kindergarten OR early years)" (36 results), "playful learning + (kindergarten OR early years)" (12 results), "inquiry + play + (kindergarten OR early years)" (31 results), "play based + (kindergarten OR early years)" (105 results), and "play + learning + (kindergarten OR early years)" (459 results). The terms 'kindergarten' and 'early years' were used as alternate keywords in order to include articles published in regions where the term 'kindergarten' is not widely used but reflects the same years of education (e.g., Hard \& O'Gorman, 2007; Roberts-Holmes, 2012). These keyword searches generated a total of 643 references (including some duplicate articles found across multiple searches). Details regarding these literature searches are outlined in table 1.

\section{Study Selection: Inclusion and Exclusion Criteria}


The abstracts of all retrieved studies were reviewed to ensure relevance to the current topic. If the abstract did not provide enough information to judge the relevance to the scoping review topic, the full text was reviewed. In order to be selected for inclusion, the article must have been retrieved from a peer-reviewed journal published between the years 2000-2016. Additional inclusion criteria related to the topic of the article rather than the format, therefore both theoretical articles (e.g., literature reviews, recommendations based on cited research, informal classroom descriptions) (e.g., Vollrath, 2007) and empirical articles (e.g., original qualitative or quantitative method studies) (e.g., Broadhead, 2009) were included. An article was included if it addressed the topic of the potential benefits of play among 4-5 year old students, or if it addressed the topic of implementing play-based learning pedagogies in early years classrooms with 4-5 year old students. A broad definition of play was used in the filtering process, allowing articles focused on teacher-directed play, child-directed play, and/or mutually directed play to be included as well as studies related to developmental and academic learning outcomes.

Exclusion criteria were developed during the article filtering process in order to exclude articles without a clear focus on the effectiveness and/or implementation of play-based pedagogies for learning in early years education. An article was excluded from review if it met any of the following exclusion criteria: (a) it was a book review or an introduction to a journal issue, (b) it focused solely on parental perspectives and/or children's perspectives of play, (c) it focused solely on outdoor play, (d) it examined preservice teachers' views on play and learning, (e) it focused on describing play without connecting it to any potential learning benefits, (f) it focused solely on teaching practices that did not emphasize play (i.e., direct instruction), (g) it focused on describing play-based curricula or policies without examining the implementation of 
that curriculum or policy, (h) it focused on assessment practices in early years education, (i) it focused solely on the potential benefits of play for children's physical development, (j) it examined play in non-educational settings (e.g., home-based studies), (k) the article was not retrievable online and/or translated into English, (l) it focused solely on music education or learning to play an instrument, $(\mathrm{m})$ it focused on targeted interventions for children with disabilities, or (n) it provided an historical overview of early years education. After reviewing the 643 retrieved articles, a total of 168 were selected to be included in the current review.

\section{Charting the Data}

Once the selection process was complete, each included article was 'charted', or sorted according to the key issues and themes of the review (Arksey \& O'Malley, 2005). In this case, the articles were organized into three emergent categories: research on play for developmental learning $(N=50)$, research on play for academic learning $(N=74)$, and factors influencing play in kindergarten classrooms $(N=44)$. In the two former sections, articles were then divided into theoretical papers and empirical studies. Articles discussing research on play for developmental learning included 22 theoretical articles and 28 empirical articles $(N=50)$, while articles discussing research on play for academic learning included 22 theoretical articles and 52 empirical articles $(N=74)$. The final category, factors influencing play in kindergarten classrooms, included qualitative studies or literature reviews examining teacher beliefs and/or current practices with respect to play and learning in early years education $(N=44)$.

\section{Results}

The two perspectives related to the role of play for developmental versus academic learning complicates play-based research representing two different orientations toward the value and potential benefits of play. Accordingly, in reporting our review of studies, we heed this 
distinction and present the results in relation to play for developmental learning and play for academic learning. Following each is a summary of factors proposed to support play with explicit focus on the role of the teacher in periods of play. Consistent with the framework set out by Arksey \& O’Malley (2005), the goal is not to assess the quality of the presented evidence but to present a thematic construction of the existing literature.

\section{Research on Play for Developmental Learning}

Theoretical studies. 22 of the 50 articles retrieved that examined play for developmental learning were classified as theoretical papers (i.e., non-empirical) and utilized personal stories or critical reflections (e.g., Hope-Southcott, 2013; Miller, 2005; L. Wood, 2014), classroom descriptions or informal observations (e.g., Andrews, 2015; Bottini \& Grossman, 2005; Hansel, 2015; Schwartz, 2008), reviews of research or other printed material (e.g., De La Riva \& Ryan, 2015; McNamee, 2005), and recommendations for classroom practice based on existing research or theories (e.g., Bodrova \& Leong, 2003; 2008; Liu, Karp, \& Davis, 2010). Twelve of these articles described multiple facets of development, including general cognitive development (e.g., Hansel, 2015), social-emotional development (e.g., Andrews, 2015), and/or self-regulation (e.g., Bodrova \& Leong, 2003). Three articles focused solely on general cognitive development (e.g., Fleer, 2011a), two articles focused solely on self-regulation skills (Bodrova \& Leong, 2008; De La Riva \& Ryan, 2015), and five articles focused solely on the development of social skills (Liu, Karp, \& Davis, 2010). With respect to the type of play addressed, 20 articles discussed the benefits of child-directed play, 9 articles discussed mutually directed play, and only 1 article discussed the benefits of teacher-directed play.

Empirical studies. 28 of the 50 articles retrieved that examined play for developmental learning were classified as empirical papers and used qualitative methods $(N=19)$ and/or 
quantitative measures $(N=10)$. Seven articles focused on the topic of general cognitive development (including meaning making or concept formation) during play (e.g., Binder, 2014; Fleer, 2011b). Four articles (Gmitrová \& Gmitrov, 2004; Vu, Han, \& Buell, 2015) examined both cognitive development and social-emotional development, 15 articles (e.g., Ghafouri \& Wien, 2005; Lim, 2012) focused mainly on social-emotional development, and 1 article focused on the development of self-regulation (Fantuzzo, Sekino, \& Cohen, 2004). One additional article examined children's perceptions on learning in general (Alvestad, 2011) but discussed the topic of learning through play mainly for social-emotional development. With respect to the type of play addressed, 24 articles examined child-directed play, 8 articles examined mutually directed play, and only 2 articles discussed teacher-directed play.

\section{Factors Supporting Play for Developmental Learning}

The 50 articles focused on play for developmental learning identified three core benefits of play in kindergarten education: (a) cognitive development, (b) social-emotional development, and (c) development of self-regulation.

Cognitive development. 14 theoretical articles and 11 empirical articles discussed how play supports different facets of general cognitive development in kindergarten students. In these cases, cognitive development included problem solving (e.g., Gmitrová \& Gmitrov, 2004; Lim, 2012), concept knowledge (e.g., Hansel, 2015), cognitive co-construction or the construction of knowledge through cooperative social interactions (Leseman et al., 2001), critical thinking skills (Andrews, 2015), and negotiating meaning or forming concepts while interacting with the environment, with a focus on the relationships between experience, imagination, and cognition (Fleer, 2011b; Fredriksen, 2012; Warner, 2009).

In the examined theoretical studies, researchers who argued for the benefits of play in 
kindergarten with respect to children's cognitive development tended to endorse the importance of different types of child-directed play, with some also endorsing opportunities for mutually directed play. With respect to child-directed play with toys, Bottini (2005) described children constructing knowledge through child-led exploration and experimentation with new materials and ideas in the classroom. Similarly, Miller (2005) and L. Wood (2014) emphasized the importance of hands-on experiences for children's construction of knowledge through their participation in centre-based activities during free playtime. Schwartz (2008) viewed childdirected pretend play as setting a foundation for future cognitive learning by giving children hands-on experiences and the potential for deeper understandings of real world concepts. High quality child-directed pretend play has also been proposed to facilitate the development of mental representations through the assignment of different meanings to objects than what they were designed for, contributing to the development of abstract thinking (Bodrova \& Leong, 2003). Free play using blocks or other constructive materials has been suggested to promote problem-solving skills through concrete experiences with the materials, and improve the understanding of more abstract concepts such as spatial relations and motion (Andrews, 2015; Hansel, 2015). Miller (2005) also recommended the use of free play with blocks and other manipulatives to help children develop critical thinking skills. Andrews (2015) proposed that children use critical thinking skills when they work towards a block-building goal, such as attempting to build a strong enough ramp for a car to pass over it. Mutually directed play was also endorsed during block play, with the recommendation that teachers talk with the children about what they are building to support the development of spatial relations through describing the positions of blocks or other objects (Hansel, 2015). Hope-Southcott (2013) and McNamee (2005) focused on the importance of mutually directed play such as following children's lead 
during toy play or pretend play and asking questions or making suggestions to support further cognitive growth.

The focus on the importance of child-directed play and facilitating cognitive development through direct experience with different materials described in theoretical articles was mirrored by the findings from empirical studies. None of the empirical studies examined block play specifically, however the concept of free, child-directed play exploring a variety of materials was commonly endorsed (Fredriksen, 2012; Nordtomme, 2012). Lim (2012) observed kindergarten children engaged in free play at a computer station and found that the children practised problem solving through trial and error with peers, which led to the children trying out new problem solving methods and practising critical thinking skills. Lim argued that child-directed play centered on computers could support young children's construction of knowledge.

Three articles highlighted the importance of imagination acting as a bridge between child-directed play and cognitive learning, a topic not directly addressed in the theoretical articles. Based on direct observations, Fredriksen (2012) found that allowing open exploration of objects without defining what should be created allowed students to negotiate different meanings and learn through direct experience with the materials, proposing things to create and encountering problems along the way that resulted in a number of natural, child-guided learning opportunities. Based on kindergarten classroom observations, Fleer (2011b) proposed that concept formation can be built during free play through the children's use of imagination to think of the particular as well as the general in a relational way. Imagination was incorporated into all of the observed play activities, and was being used by the children to gain a better understanding of the real world. Similarly, Leseman et al. (2001) looked at cognitive co-construction, or the construction of knowledge through cooperative social interactions, and found that cooperation 
during pretend play with low teacher involvement was related to more verbal interactions on a higher mean cognitive distancing level than during times of assigned cooperative work (verbal behaviours such as giving analytical or explanatory reasoning, discussing abstract principles, reasoning about rules, or discussions related to a pretend scenario). Although only 12 minutes of each activity were analyzed in-depth, these researchers argued in favour of child-directed pretend playtime to enhance cognitive co-construction.

Gmitrová and Gmitrov (2004) compared child-directed pretend play in small groups against teacher-directed pretend play in a whole group and found an increase in cognitive behaviours related to problem solving (e.g., asking a question, stating a problem, suggesting a solution) during child-directed pretend play relative to the teacher-directed play condition. One proposed explanation for this finding was that the children's persistence gradually decreased during the teacher-directed pretend play, indicating a potential decrease in motivation that was not present in the child-directed pretend play (Gmitrová \& Gmitrov, 2004). These researchers argued in favour of providing opportunities for child-directed pretend play to support cognitive competence in kindergarten. In an experimental study in support of free play, McInnes, Howard, Miles, and Crowley (2010) presented students with a general problem-solving task that the children were familiar with (a bead task, the details of which were not described) in both a playful condition (element of choice, adult proximal) and in a formal condition (task presented to the student with an adult present). Overall, the children were found to demonstrate superior performance on this problem-solving task in the playful condition compared to the formal condition, and so the researchers cautioned teachers getting involved in children's play (McInnes et al., 2010). 
Alternatively, three empirical articles endorsed the use of mutually directed play strategies to facilitate cognitive development (Siraj-Blatchford \& Sylva, 2004; Vu et al., 2015; Walsh et al., 2006). In a study that looked at teacher-child play interactions before and after a teacher-training program, $\mathrm{Vu}$ et al. (2015) found that the teachers got more involved in the children's play post-training to help increase both the cognitive play level and the social play level. However, these researchers warned against too much teacher direction in play, and discussed witnessing the use of play "inappropriately as a medium for academic learning" (p. 455), conceptualizing play as solely a vehicle for developmental learning. Alternatively, Walsh et al. (2006) found that an enriched play-based curriculum that incorporated all three types of play scored higher on the Quality Learning Instrument (QLI) compared to a curriculum that prioritized direct instruction. Scores on the QLI reflected general cognitive and social measures such as higher order thinking skills, concentration, well-being, and social interaction (Walsh et al., 2006). Although this finding supports the use of a range of play types, the majority of empirical articles focused on general cognitive development emphasized the importance of childdirected play.

Social-emotional development. 14 theoretical articles and 20 empirical articles addressed the benefits of play for social-emotional development in kindergarten. Social-emotional development refers to the development of social and emotional competencies, including cooperative skills (e.g., Andrews, 2015; Tal et al., 2008), social interactive behaviours (e.g., Bodrova \& Leong, 2003; Liu et al., 2010), feelings of capability (Binder, 2014; Lim, 2012), social identity construction (Chafel, 2003; Vollrath, 2007), positive peer relationships (McNamee, 2005), and social literacy skills, defined by researchers as the creation and navigation of social rules during play (Ghafouri \& Wien, 2005). 
The majority of recent theoretical articles examining the role of play in kindergarten have argued in favour of child-directed play for positive social-emotional development, with one exception arguing in favour of teacher-directed play. In general, free play with children in groups has been endorsed as an important way to foster social skills with peers (Hope-Southcott, 2013). Bottini (2005) described the importance of allowing children the opportunity to help each other solve social problems as they arise during free play without teacher assistance in order to build social skills. Free play in groups with blocks in particular was linked to the development of cooperative play skills, social skills, and language skills (Andrews, 2015; Hansel, 2015). Five of these articles specifically endorsed child-directed pretend play, with two of these articles also endorsing mutually directed pretend play scenarios. Encouraging pretend play in the classroom has been emphasized as a strategy for building a positive and supportive classroom community (McNamee, 2005). When children are given opportunities to try different roles through childdirected pretend play, they learn about social interactions they might not have in the real world, and teachers can help extend this play by talking to the children about different people and roles in the community (Bodrova \& Leong, 2003). Hansel (2015) endorsed the use of blocks or other constructive materials, highlighting that these can also be used for pretend play purposes to help develop social and emotional competence. Mutually directed pretend play, through the teacher asking children to share stories and then taking turns acting out the stories (referred to as the storytelling curriculum), was highlighted as a way to build positive relationships between peers as well as adults by working through issues of debate, concern, or reflection together in the classroom (McNamee, 2005). In contrast, one article pointed to the potential benefits of teacherdirected physical games for fostering social responsibility and positive social skills (Liu et al., 2010). These researchers proposed that teachers can design physical games such as variations on 
musical chairs and cooperative tag games that require children to practise specific social interactions such as cooperating, helping, sharing, and respecting others. Teacher-directed play was thought to allow children to integrate social interactive behaviours to get along with peers leading to the development of friendships (Liu et al., 2010), however no articles were retrieved on the subject of examining the proposed model empirically. Overall, the majority of theoretical articles focused on the importance of free play for developing social-emotional competence, with many highlighting the value of pretend play.

Similarly, the majority of empirical articles (16) that addressed the topic of play and socialemotional development in kindergarten examined child-directed play, while 4 articles examined types of mutually directed play and 2 discussed teacher-directed play (in conjunction with other play types). Researchers have pointed to the importance of child-directed play with peers to help children develop important social and emotional competencies in these early years. In one study, four different types of social literacy skills were observed during child-directed play, which the authors' proposed helped the children to sustain the play and develop a sense of 'we' in the play group separate from adults (Ghafouri \& Wien, 2005). These included leading and following the rules of play, supporting the emotional well-being of play partners, including others in play through the use of props, and resolving conflicts through the use of humour, flexibility, and following a leader (Ghafouri \& Wien, 2005). These authors proposed that children practise important and complex social skills during free play so teachers should encourage and protect this type of play in the classroom. Alvestad (2011) found that many kindergarten students reported developing social and emotional competencies such as empathy, cooperation, friendship, self-esteem, and personal identity through free play with their peers. A shift from more formal learning in the classroom to the development of a kindergarten culture with play at 
its core was then proposed in order to foster this social-emotional learning (Alvestad, 2011).

Lending support to Bottini's (2005) proposal that it is important for children to solve social problems amongst themselves, Fredriksen (2012) found through observations and interviews that children felt competent and self-confident when they encountered problems and then attempted to solve these problems without teacher assistance. In one study, through enhancing the play environment, engaging in discussions with the children, and following the children's lead with respect to current interests and experiences in their lives, researchers working collaboratively with teachers were able to enhance the quantity and the quality of children's pretend play in a kindergarten classroom, with the teachers reporting more observed cooperation, more complex discussions, and more mutual emotional support among the students after the changes were implemented. The richer pretend play was reported by the teachers to have improved the overall social climate of the classroom (Tal et al., 2008). Kindergarten students were also found to engage in positive social interactions during free play at a computer station, including the exchange of information, helping each other solve problems, and examining things from the perspectives of others. It was argued that rather than promoting social isolation, computer stations in the classroom can support meaningful interactions among peers that supports children's social development (Lim, 2012).

With respect to mutually directed play, researchers found that teachers endorsed the idea of facilitating play-based activities both in the classroom and in the community to help foster a sense of belonging in kindergarten among Chinese immigrant children living in Hong Kong (Ebbeck et al., 2010). This included pairing children up during play according to their language background in order to provide social and emotional support, as reported by the teachers. Another study promoted teachers' use of a version of the storytelling curriculum that encouraged 
children to share stories in groups utilizing different modalities (e.g., orally, dramatically, through visual art) in order to help strengthen connections between students (Binder, 2014). During mutually directed play activities, caring interactions between students were observed, and the teachers reported positive changes in the children's social interactions (Binder, 2014).

Two retrieved articles endorsed the use of teacher-directed play to facilitate socialemotional development, alongside free play and mutually directed play. In addition to the Walsh et al. (2006) study outlined previously, Howard, Miles and Rees-Davies (2012) found that teachers in kindergarten classrooms in South Wales integrated computers into a variety of playbased learning activities (all three types of play) and teachers reported that these activities contributed mainly to the students' social and emotional development. However, no explicit outcome measures were utilized. Overall, empirical articles on the topic of social-emotional development were heavily focused on the benefits of promoting child-directed play in the classroom.

Self-regulation. Although many definitions of the term self-regulation have been put forward by researchers (De La Riva \& Ryan, 2015), it has been practically defined as an internal mechanism that allows individuals to both control an immediate impulse or stop doing something when needed (e.g., shouting out an answer to a question posed by a teacher) as well as engaging in a less desirable behaviour in order to accomplish a goal (e.g., raising one's hand to be chosen to speak) (Bodrova \& Leong, 2008). In short, self-regulation is the ability to control one's own behaviour (Shanker, 2010), and can extend to a variety of domains, such as biological, emotional, cognitive, and social (De La Riva \& Ryan, 2015). Six theoretical articles addressed the topic of play and self-regulation in kindergarten and only one retrieved empirical article explicitly focused on self-regulation. These articles focused on the emotional, cognitive, and 
social domains of self-regulation involved in task such as following rules (e.g., Bodrova \& Leong, 2008; De La Riva \& Ryan, 2015), regulating emotions (e.g., Miller, 2005; Nicolopoulou, 2010), and planning future behaviours (Bodrova \& Leong, 2003).

All six theoretical articles addressing the topic of play and self-regulation development endorsed the importance of child-directed play for practising and enhancing these skills, with one article also mentioning the importance of mutually directed play. In an integrative review of the literature, De Le Riva and Ryan (2003) recommended two different types of child-directed play; pretend play and rough-and-tumble physical play, as strategies for improving self-regulation skills in kindergarten-aged children. These researchers cited past research that lent support to the idea that children learn how to regulate emotions while they negotiate the rules, circumstances, and direction of their play (De La Riva \& Ryan, 2015). Researchers have argued that children best learn to self-regulate when they themselves negotiate, create, and follow rules during pretend play as well as made up games (Bodrova \& Leong, 2008). Additionally, Bodrova and Leong argued that teachers should focus on discussing pretend play with the children before it begins, including the assigned roles and the theme of the play, to help children monitor and plan their own behaviours that can help sustain the pretend play scenario for longer periods (Bodrova \& Leong, 2003). Miller (2005) emphasized that teachers should not try to separate children who may get too loud or excited around each other, but rather to try and teach children to monitor their own behaviours during play by providing a balanced schedule, a wide array of appropriate play materials, and opportunities for small group interactions. It was recommended that kindergarten teachers maintain an environment centred on child-directed play in order to improve outcomes related to self-regulation, over and above teacher-directed play (De La Riva \& Ryan, 2015). Although Nicolopoulou (2010) highlighted some of the self-regulation benefits of 
child-directed play, it was also mentioned that integrating play elements into the curriculum could promote positive learning and development, however explicit strategies for accomplishing this were not outlined.

Only one retrieved empirical article explicitly addressed the topic of play and selfregulation in early years education. Fantuzzo et al. (2004) examined child-directed play interactions in children from 46 Head Start classrooms in the northeast United States, measuring two dimensions of self-regulation (emotion regulation and autonomy). In general, children who demonstrated higher levels of peer play interactions during periods of child-directed play were found to engage in higher levels of emotional regulation skills in the classroom (Fantuzzo et al., 2004). These children were more likely to share, take turns, and less likely to grab another child's toy during moments of conflict. The authors stated that this study emphasizes the importance of encouraging child-centred play to promote positive child development. However, only one empirical article was retrieved on the topic of play and self-regulation in the kindergarten years across all literature searches so the evidence is limited. This could reflect a lack of studies on play and self-regulation currently published in journals focused on educational research.

Role of the teacher in play-based developmental learning. Across all areas of developmental learning, theoretical and empirical studies have endorsed the role of the teacher as one who provides an abundance of appropriate play materials (Hansel, 2015; Miller, 2005; Schwartz, 2008), provides blocks of uninterrupted time for children to engage in free play (Fredriksen, 2012; Gmitrová \& Gmitrov, 2004; Hansel, 2015; McNamee, 2005; Nordtomme, 2012), and extends children's play and learning by getting involved in play when appropriate without transforming it (Andrews, 2015; Bodrova \& Leong, 2003; Fredriksen, 2012; Ghafouri \& 
Wien, 2005; Gmitrová \& Gmitrov, 2004; Hansel, 2015; Nordtomme, 2012). By taking the passive role of facilitator of child-directed play through providing materials and allocating blocks of time, it is proposed that children are able to practise problem solving skills (Fredriksen, 2012; Lim, 2012), gain social competence with peers (Andrews, 2015; Bottini, 2005; Fredriksen, 2012; Ghafouri \& Wien, 2005; Hansel, 2015), and create different representations of their ideas which encourages abstract thinking (Hansel, 2015; Schwartz, 2008). In these cases, it is argued that children practise these skills in the absence of teacher involvement, and this involvement is often explicitly referred to as a disruption to the positive influence of free play (Fredriksen, 2012;

Ghafouri \& Wien, 2005; Lim, 2012; Nordtomme, 2012).

While some articles also endorsed the use of mutually directed play for developmental learning, teachers were still encouraged to follow the children's lead and avoid having too much influence over the play. For example, it was recommended that teachers "gently" (Gmitrová \& Gmitrov, 2004, p. 278) enter the play process in order to further enhance cognitive development. Similarly, Nordtomme (2012) stated that the teacher's role can shift from observer to active player, but should remain "withdrawn from the centre of the play" (Nordtomme, 2012, p. 330). $\mathrm{Vu}$ et al. (2015) provided a warning for teachers about getting too involved in play activities, stating "we would hope that with time, teachers would learn to moderate their involvement and remain in the higher facilitative roles without overstepping boundaries and completely taking over children's play" (p. 455). With respect to pretend play, it was recommended that teachers discuss different potential roles, play themes, and the use of different props in order to enhance this type of play and encourage further self-regulation development (Bodrova \& Leong, 2003; 2008) and general cognitive development (Bodrova \& Leong, 2003; Schwartz, 2008).

Furthermore, it was suggested that teachers could encourage children to share stories in the 
context of play in order to foster an emotionally supportive classroom environment (Binder, 2014). As an exception, one theoretical article recommended that teachers take an active role in the teaching of social interactive behaviours through directly leading physical games with concrete rules for the children to follow (Liu et al., 2010). Overall, theoretical and empirical articles on the subject of developmental learning highlighted the importance of teachers acting as observers and facilitators of child-directed play, endorsing this type of play as an important part of kindergarten pedagogy that should be preserved without significant disruption.

\section{Summary of Research on Play for Developmental Learning}

Recent articles that have addressed the potential benefits of play for developmental learning (i.e., social-emotional development, general cognitive development) in kindergarten have generally endorsed the use of child-directed free play in the classroom in order to practise and enhance skills in different areas of development. Both theoretical and empirical articles described the optimal role of the teacher as a passive observer of play who sets up an environment that encourages rich free play and allows children to direct their own play activities. These free play opportunities, including both free play with toys and child-directed pretend play, have been supported both theoretically and empirically as an important component of kindergarten that shapes positive developmental learning.

\section{Research on Play for Academic Learning}

Theoretical studies. 22 of the 74 articles retrieved that examined play and academic learning in kindergarten did not contain any empirical investigations and were therefore classified as theoretical papers. The formats utilized in these articles included informal descriptions of classroom activities (e.g., Cohen, 2009; Damian, 2005; Isom, 2014; McLennan, 2012; Rothman, 2006; Sharp, Escalante, \& Anderson, 2012), descriptions of play-based learning 
strategies (e.g., Balfaz et al., 2003; Cooper, 2005; Kamii, 2003), and recommendations for classroom practice based on cited research and curricular expectations (e.g., Newbury et al., 2015; Riek, 2014; Sarama \& Clements, 2006). Eleven of these articles described the learning of general academic skills (e.g., Damian, 2005), six articles discussed the learning of literacy skills (Rothman, 2006), and five articles described the learning of foundational math skills (e.g., Kamii, 2003). With respect to the type of play addressed, seven articles discussed the benefits of teacher-directed play, 15 articles discussed the benefits of mutually directed play, and only two articles discussed the benefits of child-directed play.

Empirical studies. 53 of the 74 articles retrieved that examined play and academic learning were empirical studies which employed qualitative $(N=33)$ and/or quantitative measures $(N=23)$. With respect to academic learning utilizing play-based strategies in kindergarten, 16 articles focused on general academic skills (i.e., multiple subjects, science-related, or specialized topic knowledge) (e.g., Edwards \& Cutter-Mackenzie, 2011), 13 articles focused on math-related skills (e.g., Wang \& Hung, 2010), and 24 articles focused on literacy learning (e.g., Ihmeideh, 2015). Due to the high number of articles retrieved on the subject of literacy learning through play, these were divided into articles with a focus on oral language development (e.g., Griva \& Sivropoulou, 2009) and articles focused on the development of early reading and writing skills (e.g., Wohlwend, 2008). With respect to the type of play addressed, 27 articles examined the benefits of teacher-directed play, 34 articles examined the benefits of mutually directed play, and only eight articles examined the benefits of child-directed play. Three of the articles that investigated child-directed play focused on the development of reading and writing skills, two focused on general subject learning (in conjunction with other types of play), one article focused on oral language skills development, and two articles focused on math-related skills 
(implemented as a comparison or control group only).

\section{Factors Supporting Play for Academic Learning}

The 74 articles focused on play for academic learning identified four core benefits of play in kindergarten education: (a) general academic learning, (b) math skills, (c) oral language skills, and $(\mathrm{d})$ reading and writing skills.

General academic learning. 11 theoretical articles and 16 empirical articles discussed the learning of general academic skills in kindergarten through play. These articles either described the benefits of play-based learning across a wide range of subjects (e.g., Damian, 2005; McLennan, 2012; Miller, Robertson, Hudson, \& Shimi, 2012; Sylva et al., 2007), or in the learning of a specific subject area such as science (Hachey \& Butler, 2009; Riek, 2014; Stoll, Hamilton, Oxley, Eastman, \& Brent, 2012), cultural-historical concepts (Cohen, 2009), geography (Catling, 2006), environmental education (Cutter-Mackenzie \& Edwards, 2013; Edwards \& Cutter-Mackenzie, 2011), and technology (Stephen \& Plowman, 2003).

The majority of retrieved theoretical articles ( 8 out of 11$)$ that discussed general academic learning in play highlighted the importance of mutually directed play activities, where some elements of the play activities were teacher-influenced and other elements were influenced by the children. Six of these articles contained informal kindergarten classroom descriptions of play-based learning activities. McLennan (2012) described what happened in a classroom after a bird feeder was erected in a window and it captured the interest of the students. The teacher provided resources on birds in the play centres and led group discussions on birds, which led to the students engaging in math and literacy-related activities such as writing down the names of birds spotted on a chart, creating a pictograph to represent how many of each type of bird had been spotted, drawing pictures of birds with written descriptions, and measuring the distance 
between bird tracks and comparing it to the distance between the children's feet when they walk (McLennan, 2012). These activities were often created by the teacher but driven by the children's interest and requests to learn more about the birds. Similarly, in one article two children were observed to be acting out a movie scene with toys, which inspired the teacher to suggest the class make their own movie (Damian, 2005). The activities were laid out by the teacher; such as writing a general story, creating sets, and acting out a script; but it was driven by the children's interest and they were given creative input at every step. Some of the academic skills practised by the children in these activities included storytelling, researching different topics, learning new vocabulary, and creating representational artwork (Damian, 2005).

In another classroom, the teachers chose a cultural theme for all of the different play centres (e.g., India, China, or Mexico) and provided materials to help guide the children's cultural learning through play (Cohen, 2009). For the Indian unit, this included setting up an Indian restaurant in the drama centre and posting a picture of the Taj Mahal in the block area, along with paper and pencils for sketching. The children were later able to list a number of facts regarding Indian food and the Taj Mahal they had learned through these play-based activities (Cohen, 2009). Riek (2014) outlined strategies for teachers to use in order to address academic standards in the curriculum in a play-based manner, highlighting the importance of following children's interest, co-constructing different learning activities with the children, and providing lots of opportunities for the children to explore different materials. A teacher is not only a material provider and play facilitator, but one who can guide the directions of the children's inquiries (McLennan, 2012), as well as co-construct play-based learning activities with the children and discuss clear connections between play and learning (Riek, 2014). In a pedagogy centred on play, teachers "become co-learners or more fittingly learning leaders" (Riek, 2014, p. 
$6)$.

Among the 16 retrieved empirical articles, the majority $(N=11)$ similarly outlined the benefits of mutually directed play strategies, while nine articles focused on the benefits of teacher-directed play or both of these types of play. In a study that examined science learning through play in the classroom, 48 sites were observed across nine countries in the European Union and some common mutually directed play strategies were endorsed (Cremin, Gluert, Craft, Compton, \& Stylianidou, 2015). It was found that in moments of playful learning, the children engaged with different resources, asked questions, and collaborated to solve scientific problems, often with teacher support. These authors proposed that these contexts provided children with opportunities to practice early scientific reasoning skills (Cremin et al., 2015). In a qualitative study by Doherty (2012), a kindergarten classroom attempted to engage in science learning through free play activities but found this to be ineffective, since the children "moved around constantly, rarely completing activities" (p. 25). The teachers then decided to get involved in the tasks alongside the children, and these mutually directed play strategies were reported to be much more effective by the teachers. In a study by Sylva et al. (2007) looking at multiple facets of academic learning, preschool classrooms that scored higher on a measure of classroom quality (that included measures of literacy, math, science and environment subscales) were observed to engage in more teacher-directed and mutually directed play activities.

Conversely, classrooms that attained medium scores on classroom quality engaged in more free play (Sylva et al., 2007). In an exploratory study on integrating game-based learning into early years pedagogy, four early years classrooms in Scotland were given a pet simulator video game (Miller et al., 2012). The children were observed to be extremely motivated to both engage with the game as well as engage in related teacher-directed play activities, including ones with writing 
and math-related components. Observers consistently noted playful lessons, integrated work, and individual autonomy in the classroom related to learning about and caring for pets (Miller et al., 2012).

Two retrieved articles discussed the use of free play in the learning of environmental education (Cutter-Mackenzie \& Edwards, 2013; Edwards \& Cutter-Mackenzie, 2011). However, these articles did not endorse free play alone, but rather a range of play-based learning strategies encompassing all three types of play, in what was termed 'purposely framed play'. In one study, kindergarten teachers in Australia received training in purposefully framed play strategies, and then practiced implementing these strategies in the classroom (Cutter-Mackenzie \& Edwards, 2013). This included open-ended play (free play), modeled play, and teacher-child interactions and engagement during play. These authors proposed that by engaging in these different play types, experience and content knowledge could be connected in the teaching of environmental education. However, they stated that it was the combination of different play types that lead to effective academic learning, as "children require more than open-ended play to experience meaningful learning in early childhood settings" (Cutter-Mackenzie \& Edwards, 2013, p. 210).

In one study that compared kindergarten classrooms that followed a play-based curriculum with classrooms that focused more on direct instruction, researchers found no significant differences on measures of literacy and numeracy outcomes seven years later, failing to empirically support the use of a play-based curriculum (McGuinness, Sproule, Bojke, Trew, \& Walsh, 2014). However, the overwhelming majority of retrieved articles did support the use of play-based learning strategies both theoretically and empirically.

Math skills. Five theoretical articles and 13 empirical articles examined and endorsed the learning of math-related academic skills through play-based learning in kindergarten. These 
math-related skills included measurement (Kotsopoulos et al., 2015), logico-mathematical thinking (Kamii, 2003), number sense (Newbury et al., 2015; Wang \& Hung, 2010), and spatial skills (Casey et al., 2008), as well as general math learning (e.g., Balfanz et al., 2003; Brandt, 2013; Lee \& Goh, 2012; Presser et al., 2015).

Three theoretical articles focused on the use of teacher-directed play activities to target the learning of math skills in kindergarten through play, while two theoretical articles focused on mutually directed play and none discussed child-directed play. In terms of teacher-directed play, one article outlined a developmentally appropriate curriculum designed to target math skills in kindergarten, called Big Math for Little Kids (Balfanz et al., 2003). In this study, the curriculum was designed to target math skills in a fun and engaging way, stimulating purposeful learning through play. The authors asserted that "children learn through play, but they can discover only a certain amount on their own" (Balfanz et al., 2003, p. 265). Some of the teacher-directed games included one where the teacher counted up from one and the children had to yell out "mistake!" if the teacher made an error. Another highlighted example involved children being given a bag with a number on it and having to go collect that number of objects, with the children later reconvening and comparing their items (Balfanz et al., 2003). In a similar teacher-directed manner, teachers in Japan modified the board game 'Sorry!' in order to target children's logicomathematical thinking in a playful way (Kamii, 2003). The game was designed for children of different abilities to play together and to make the level of logico-mathematical thinking each player was using very clear, with a teacher present to give suggestions or ask probing questions to assist each child to move up to the next level of thinking (Kamii, 2003).

Other researchers gave recommendations for teachers to target the development of number sense through teacher-directed play (Newbury et al., 2015). For example, through the use of 
games where children grabbed handfuls of objects and tried to say how many were present without explicitly counting them, and through linear board games rather than circular board games to help children estimate numbers on a number line (Newbury et al., 2015). These researchers emphasized that "allowing children just to play without an intentional math focus does not provide meaningful opportunities" for math learning (Newbury et al., 2015, p. 13). Another article discussed the importance of mutually directed play activities through allowing child-led exploration with constructive materials such as blocks and then having teachers “meaningfully intervene as needed to further children's learning" (Sarama \& Clements, 2006, p. 41). They recommended that teachers pose challenges, post pictures of different constructions, help children discuss or clarify ideas, and introduce relational terms such as tall or short into the play (Sarama \& Clements, 2006). Theoretical articles on the subject of math learning through play tended to focus on teacher-directed play through the use of board games or teacher-led group games with rules explicitly laid out by the teachers, as well as through more mutually directed play by intervening in children's constructive play to extend their math learning. Empirical articles on the topic of learning math-related skills through play support and extend the recommendations made in theoretical articles, endorsing the use of teacher-directed and mutually directed play for the learning of a variety of math concepts in kindergarten. Outcomes from the Big Math for Little Kids curriculum outlined by Balfanz et al. (2003) was examined by Presser et al. (2015) across 16 different schools over a two year period and found the scores of children in the intervention classrooms increased significantly more than comparison classrooms on a general assessment of math skills, equivalent to 2.9 additional months of instruction. This curriculum emphasized the use of teacher-directed play activities such as games, stories, and activities with manipulative objects in order to target math units such 
as spatial relations and number operations (Presser et al., 2015). These researchers emphasized that "[free] play is not enough-children can only go so far on their own" (p. 407). With respect to teaching number sense, or the understanding of the meaning of numbers and their relationships, a teacher-directed board game was run with a group of four students in a kindergarten classroom for eight weeks, with the intervention group performing significantly better than a control group on almost all items of a standardized math test assessing number sense (Wang \& Hung, 2010). The children were observed to participate enthusiastically in the game, and this teacher-directed play activity was recommended as a useful tool for teachers to engage children in math learning. Mutually directed pretend play was recommended by Lee and Goh (2012) as a strategy for helping children learn money math, detailing a project where children in a kindergarten class collaborated with teachers in constructing food stalls so they could buy and sell food with their peers. The children involved reported feeling more confident about purchasing food, but demonstrated varying proficiencies with monetary transactions by the end (Lee \& Goh, 2012). Brandt (2013) observed different teacher-directed and mutually directed play activities in a German kindergarten classroom, where different perspectives on who held responsibility for general math learning (the adult, the child, or both) were demonstrated with common play objects. In a teacher-directed play activity involving the assembling of patterns with coloured pegs, learning was observed to be under the responsibility of the adult, however in the observed mutually directed activities, learning was classified as either being under the responsibility of the child or both the adult and child (Brandt, 2013). In all three play examples highlighted, "no free experimentation with the objects takes place, but rather directed mathematical activities using them" (Brandt, 2013, p. 240), emphasizing that teachers could direct the play activity but still place some of the responsibility for learning on the participants. 
Two empirical articles addressed the topic of free play as a comparison group against other types of play in the classroom. In a direct comparison of different play-based learning pedagogies, one study examined the learning of length measurement and investigated the effects of all three play-based learning approaches (teacher-directed, mutually directed, and free play) in three different kindergarten classrooms (Kotsopoulos et al., 2015). However, no significant performance differences on a measurement task were found between the groups after two weeks, aside from the finding that the older children performed better on the task than the younger children, suggesting that age rather than pedagogical approach may be more influential in the learning of length measurement (Kotsopoulos et al., 2015). In spite of this, the authors believed that "play without any explicit pedagogical intent or teaching may be insufficient" to develop math-related concepts (Kotsopoulos et al., 2015, p. 537).

In another study that utilized free block play as a control condition, teacher-directed block play with and without a story condition were compared across six classrooms for eight weeks (Casey et al., 2008). In the story condition, the children were directed to build different structures from a dragon puppet in order to help a king and queen, while in the no-story condition the children were instructed to build the same structures without an explicit rationale. Children who were led through the block activities with a story performed significantly better on measures of block building, while children in both teacher-directed block play conditions improved significantly on measures of block design compared to the free play control group, lending support to the idea that teacher direction in block play may improve children's spatial skills (Casey et al., 2008). Overall, researchers who examined the learning of math skills through play emphasized the use of teacher-directed and mutual directed play activities, with many empirical results supporting this type of play in kindergarten. 
Oral language skills. Oral language development refers to the skills involved in effective oral communication with others, and it has been highlighted as a foundational literacy skill (e.g., Sharp et al., 2012) that serves as a starting point for later literacy development such as reading ability (Woodard, Haskins, \& Schaefer, 2004). Early primary education has also been cited as a critical period for students to develop oral language skills in a second language (Caner, Subasi, \& Kara, 2010; Griva \& Sivropoulou, 2009). Four theoretical articles and 11 empirical articles addressed this topic (e.g., Woodard et al., 2004).

Two theoretical articles that addressed the topic of learning oral language skills through play highlighted mutually directed play activities, one article highlighted the importance of teacher-directed play activities, and one article highlighted both mutually directed and teacherdirected play. Cooper (2005) discussed a classroom that used the storytelling curriculum where children made up stories, the teacher recorded the stories, and then the children acted them out. It was argued that this curriculum potentially impacts oral language development through openended conversations between teacher and child regarding the child's story (Cooper, 2005). For example, the teacher can read back the story as dictated by the child so that the child can hear it and fix any mistakes in their previous oral dictation (Cooper, 2005). The final part, dramatization, is also important for oral language development as it required the children to speak for different characters (Cooper, 2005). Another article highlighted the importance of dramatic play in the development of literacy skills, including oral language skills, and outlined a teacher-directed game where the instructions to the children all ended in the '-op' sound (Sharp et al., 2012). For example, "hop to a shop to get free pop" (Sharp et al., 2012, p. 16). After this teacher-led game, the children discussed the new theme of the dramatic play centre with the teachers and were given the opportunity to engage with the materials. The authors argued that 
"the influence of the strong phonologically based literacy instruction stimulates children's choice of words during play as they practice generating rhymes and incorporating them" into the play (Sharp et al., 2012, p. 17). Both of these theoretical articles pointed to collaboration with the students through mutually directed play activities to target oral language development, as well as some teacher-guided play activities to address early literacy skills (Sharp et al., 2012).

Four empirical articles addressed the topic of targeting oral language skills development through play while seven empirical articles focused on developing oral language skills related to speaking a second language through play in kindergarten. Supporting the arguments made in the theoretical papers, nine of the retrieved articles discussed benefits related to mutually directed play, three of the articles supported the use of teacher-directed play activities, and only one article examined child-directed play (but endorsed more teacher involvement in play). Preliminary qualitative results of an examination of the 'Let's Talk' project designed to target children's oral language skills through pairing up fluent speakers with less fluent speakers for play times with special toys appeared positive, with the teachers reporting vocabulary growth and greater sentence length and structure in the children's oral communication (Woodard et al., 2004). Although the play time itself was child-directed, elements before and after those times were teacher-directed, with teachers introducing a new toy category each week, modeling ways to use the toys, discussing new vocabulary words, and scheduling sharing time after the play where the children talk to the teacher about what happened during their play (Woodard et al., 2004). Van Oers and Duijkers (2013) examined the learning of new vocabulary words in two different early years classrooms: one following a play-based learning approach and one following a direct instruction approach. Post-intervention, the children in the play-based classroom (that engaged in mutually directed play activities) were observed to utilize the newly 
taught theme words in their oral language more frequently than the children in the direct instruction classroom, supporting the use of mutually directed play for promoting oral language development.

With respect to learning to speak a second language, one study conducted interviews and observations with two teachers in Turkey to see how those teachers taught the English language through play (Caner et al., 2010). Both teachers used a variety of teacher-directed activities, such as flashcard-based games and teaching the lyrics to English songs, as well as a number of mutually directed activities such as colouring a picture while naming the colours and simple pretend play games involving the acting out of a word or phrase in English (Caner et al., 2010). Participation in these activities was not mandatory, however all of the children were observed to participate, pointing to a high level of interest and motivation (Caner et al., 2010). Two new pilot projects that targeted the learning of English as a second language in kindergarten were also examined. One project involved both teacher-direct play activities, such as a game where children rolled a picture cube and then had to discuss what picture was rolled, as well as mutually directed play activities, such as "guided role play" (Griva \& Sivropoulou, 2009, p. 86). Play was utilized as the mode of learning since it is a "powerful, flexible, amusing and pleasant learning experience which promotes oral communication" (Griva \& Sivropoulou, 2009, p. 80). In the guided role play, children were asked to perform a pantomime in pairs of a word or phrase that had been introduced, and this evolved into more advanced role-playing scenarios with dialogue. These types of role playing activities were described as extremely motivating endeavors that had the benefit of practising oral English language skills, and the children in both pilot classrooms scored significantly higher on a post-test of oral language skills compared to a pre-test (Griva \& Sivropoulou, 2009). In the second pilot project, a specially trained teacher 
engaged in mutually directed play activities focused on teaching English to a kindergarten class in Norway (Elvin et al., 2007). A variety of play-based activities were used, including songs, games, role playing, stories, and making crafts, often organized by the teacher but occasionally initiated by the children themselves. In this curriculum, the teacher "prepares and leads the activities, but it is the children who are active" (Elvin et al., 2007, p. 74). Observations and logbooks demonstrated that the children had learned many English words and expressions by the end of the project.

In contrast, Piker (2013) examined children's practicing of oral language skills in free play scenarios among Spanish-speaking children learning to speak English. Although some positive scenarios were highlighted, it was pointed out that only a few opportunities to learn through play were evident and it was recommended that teachers get involved in the play to extend English language learning by grouping children together and mediating social interactions (Piker, 2013). Overall, empirical articles that addressed the development of oral language skills through play highlighted both the importance of mutually directed and teacher-directed play activities to capture children's interests and provide an abundance of guided practice in oral communication.

Reading and writing skills. Four theoretical articles and 15 empirical articles addressed the topic of learning literacy skills related to reading and writing development in kindergarten through play, including conventions of print (e.g., Cooper, 2005), phonemic awareness (e.g., Regush, Anderson, \& Lee, 2002), reading comprehension (e.g., Sharp et al., 2012), and writing behaviours such as invented spelling (e.g., Ihmeideh, 2015).

All four theoretical articles endorsed the role of mutually directed play activities in the development of early reading and writing skills in kindergarten, with one also endorsing teacherdirected play activities. Two articles described the storytelling curriculum in kindergarten, based 
around mutually directed storytelling and pretend play, and argued that dictating and acting out stories provides both direct and indirect opportunities for children to learn about print, narrative, and comprehension skills that support reading (Cooper, 2005; Rothman, 2006), as well as encoding and decoding words, vocabulary development, narrative form, and reading for meaning (Cooper, 2005). For example, a child can dictate a story to the teacher, then the teacher can read it back to the child, discuss the child's choice of words, point out grammatical mistakes, and clarify the child's intended meaning of the story (Cooper, 2005). It was also suggested that teachers could write the stories in large print for the children to read along as it is written, setting the stage for later independent writing (Rothman, 2006).

In a similar focus on pretend play, teacher-directed and mutually directed activities involving phonologically-based literacy games (e.g., focusing on one particular word sound and discussing different examples of that sound in words) with pretend elements was suggested as a method to promote reading readiness and comprehension, as well as the placement of writing materials in play centres to promote writing skills in the creation of labels and signs (Sharp et al., 2012). An examination of a class-wide mutually directed project, led by the teacher but with creative input from the students, involving the creation of children's own picture books observed children "deeply engaged in the writing process" (Isom, 2014, p. 45-46). Here the teacher read books and made observations about the pictures in the books with the students, supporting children to create their own books and share them with each other. The importance of providing writing materials and modeling writing, such as making lists, was emphasized in order to promote more writing practice during play (Isom, 2014). Similar to the retrieved articles on promoting oral language skills, theoretical papers on the development of reading and writing skills in kindergarten through play focused on the important role of mutually directed and 
teacher-directed play activities.

In contrast, empirical articles on the development of reading and writing skills in kindergarten highlighted the benefits of all three types of play, with the majority of articles focused on mutually directed play activities. However, these different types of play tend to be investigated separately with a lack of studies integrating different play types in order to enhance learning. With respect to teacher-directed play, researchers compared an intervention classroom that engaged in teacher-led literacy play centred around a frog puppet and two new play centres (an office and a library) in order to teach phonemic awareness against a control classroom that engaged in direct literacy instruction followed by free play (Regush et al., 2002). After seven weeks, the children in the intervention classroom were found to utilize significantly more phonemic strategies in their play compared to children in the control classroom, leading the researchers to conclude that teacher-supported play can enhance phonemic awareness (Regush et al., 2002).

One qualitative study that examined the role of teachers in promoting literacy development through play highlighted examples of all three types of play across five different classrooms, however the majority of examples highlighted the importance of teacher-directed activities such as literacy-focused games, songs, and activities designed by teachers (Saracho, 2002). Nonetheless, teachers were also observed to act as learning centre monitors, elaborating or changing children's play when appropriate in order to enhance literacy learning (mutually directed play) as well as giving the children space when needed (free play) (Saracho, 2002). In an article focused on mutually directed play, children's spontaneous play was observed during teacher-led writing workshops in a kindergarten classroom and researchers found that children incorporated playful elements into writing activities such as expressing emotions and engaging in 
pretend play, serving the functions of creating deep engagement with writing, helping each other revise texts, and practising different workshop-related routines (Lysaker, Wheat, \& Benson, 2010). The children were given the opportunity to engage in play that revolved around the teacher-directed writing activity, and therefore may be considered a form of mutually directed play.

Alternatively, other researchers have focused on the importance of allowing children to guide their own play, but also having the teacher scaffold in literacy learning during these play times (Korat et al., 2002; Wohlwend, 2008). "By reading to and discussing books with children, encouraging children to take risks and try their self-invented spelling, and fostering children's sociodramatic play connected to symbols and print", adults can help children build on literacy knowledge through play (Korat et al., 2002, p. 387). In one example, a group of boys in a kindergarten classroom drew pictures of their favourite sports teams, so the teacher encouraged and helped the children to write and draw books of recent sporting events, create scoreboards, and write scripts for short football movies; incorporating more writing practice into their play (Wohlwend, 2008). These examples illustrated a type of mutually directed play where the teacher followed and expanded on the children's interests rather than beginning with a predesigned activity. With respect to child-directed play, researchers have pointed to the importance of setting up a literacy rich environment with writing materials and centres that emphasize writing activities (Ihmeideh, 2015; Yoon, 2014), as well as allowing children to interact with the same materials present during more formal literacy lessons (Yoon, 2014). By allowing children space to engage in free play in a rich environment, "writing moved beyond a single event that happened only during designated workshop time," (Yoon, 2014, p. 119) and children were observed practising writing during times of play. Researchers also found that a literacy-rich 
environment with an abundance of writing materials led to more observed writing during play, compared to a classroom with fewer writing materials integrated into the play centres (Ihmeideh, 2015). However, only free play episodes were examined in these two classrooms and so comparisons between types of pedagogical approaches (or the integration of different play-based strategies) were not investigated. Compared to all other areas of learning, recent empirical articles focused on the learning of reading and writing skills through play have examined the broadest definitions of play, however they are often examined in isolation and few have pointed to the need to utilize multiple different types of play in kindergarten to promote early literacy learning.

Role of the teacher in play-based academic learning. Both theoretical and empirical articles on the subject of academic learning emphasized the importance of teachers taking an active role in children's play, both through directing play activities as well as getting involved in child-led play, in order to effectively incorporate academic learning in play. Through the use of academic board games (Kamii, 2003; Newbury et al., 2015; Wang \& Hung, 2010) and guided play activities (Presser et al., 2015; Sharp et al., 2012), it is proposed that teachers can further students' math and literacy skills in a playful and engaging manner. It is argued that teachers should act as co-participants in play-based learning activities in order to observe children's thinking and capitalize on opportunities to facilitate academic learning (Kamii, 2003; Wang \& Hung, 2010). Other studies have emphasized the importance of mutually directed play, where both teachers and children have input in the play activities. For example, Korat et al. (2002) stated that in their view, with respect to the learning of reading and writing skills, "teacher or adult intervention that takes into consideration the children's point of view, involves their interests, and leaves them room to work out their own solutions, rather than explicit teaching, is 
the preferable path" (p. 392). It is argued that teachers can work with children to infuse important math and literacy skills into play by collaborating with students in play centres (Casey et al., 2008; Isom, 2014; Lee \& Goh, 2012; Saracho, 2002; Sharp et al., 2012).

The role of the teacher in effective mutually directed play is described as a provider of “appropriate adult scaffolding and support” (Regush et al., 2002, p. 245), and this can occur through asking questions, encouraging discussion, introducing new concepts, and modeling literacy and math behaviours (Elvin et al., 2007; Griva \& Sivropoulou, 2009; Isom, 2014; Sarama \& Clements, 2006; Woodard et al., 2004). In contrast, a few retrieved articles on the subject of reading and writing development emphasized a more passive role of the teacher as a space creator and material provider, pointing to the importance of providing children with opportunities to engage in free play in enriched literacy environments (Ihmeideh, 2015; Yoon, 2014). This is in direct contrast with the vast majority of articles retrieved on the topic of play and academic learning, and few researchers have yet to address these opposing recommendations in the literature. Overall, theoretical and empirical studies have commonly endorsed teachers taking an active role in play, both through the facilitation of play activities as well as collaborating with children during play, in order to enhance academic learning in the kindergarten classroom.

\section{Summary of Research on Play for Academic Learning}

Recent articles that have addressed the potential benefits of play for academic learning (i.e., math skills, literacy skills) in kindergarten have consistently highlighted the important role of teacher-directed and mutually directed play activities in promoting early academic learning. In both theoretical and empirical studies, researchers have recommended that teachers take an active role during play times through creating and directing a variety of play activities, as well as 
regularly intervening during child-led play in order to capitalize on important learning opportunities. Teacher-directed and mutually directed play are commonly endorsed as important in early academic learning over and above what can be accomplished through free play alone.

\section{Factors influencing the Implementation of Play}

In total, 44 retrieved articles investigated or reviewed research on teacher beliefs and/or classroom practices in kindergarten in order to highlight current discrepancies and challenges with respect to implementing play-based learning pedagogies. As with the current disagreements present in the research community regarding views on play and learning, educational providers have also reported tensions and divides with respect to the role of play in the classroom. Studies that have examined classroom practices and teacher perspectives span a wide number of countries, including Canada (e.g., Pyle \& Bigelow, 2015), Germany (e.g., Wu, 2014), China

(e.g., Pui-Wah \& Stimpson, 2004), New Zealand (e.g., Foote et al., 2004), Ireland (e.g., Walsh \& Gardner, 2006), Turkey (Aras, 2016), Greece (Nikolopoulou \& Gialamas, 2015), United Arab Emirates (e.g., Baker, 2014a), and India (e.g., Hedge \& Cassidy, 2009). Although many address the influence of unique cultural factors, some common themes have emerged across these studies, including difficulties integrating the concepts of play and learning (e.g., Vong, 2012), observed discrepancies between practices and reported beliefs (e.g., Kim, 2004), and reported barriers to the effective implementation of play-based learning strategies (e.g., Hu et al., 2014).

Perspectives on the role of play and learning. 17 retrieved articles highlighted differing beliefs of teachers regarding the role of play in early learning. Nine of these articles found that teachers in China, United Arab Emirates, Northern Ireland, Wales, and Canada reported finding it difficult to integrate the concepts of play and learning, instead viewing them as separate constructs (e.g., Baker, 2014a; Lynch, 2014; Vong, 2012; Walsh \& Gardner, 2006). In these 
retrieved articles, this dichotomous perspective was the most commonly reported view regarding play and learning, with teachers reportedly struggling to see how play activities can lead to learning (e.g., Fung \& Cheng, 2012). In focus groups with 62 teachers in Abu Dhabi, teachers acknowledged the importance of play in kindergarten but interpreted it differently, with about half of the teachers equating play with free play that was not prioritized as highly as academic work, with one teacher reporting "there is not enough time in the day to play" (Baker, 2014a, p. 1836). Similarly, kindergarten teachers in Canada whose social media postings were examined "viewed the play-based curriculum as a threat to children's academic development" (Lynch, 2014, p. 339), with one teacher stating that she hoped that the ministry will allow teachers to "find a balance of academics and play" across the school day (p. 339). These perspectives highlight a conceptual division between play and academic learning. In some instances where this division has been highlighted, play has been described by teachers as a means for capturing children's attention, curiosity, positive mood, or to be used as a reward for work, rather than as a means to develop knowledge (Fung \& Cheng, 2012; Pui-Wah, 2008; Vong, 2012; Wu \& Rao, 2011). This illustrates a view of play as peripheral to learning rather than as a vehicle for learning (Pyle \& Bigelow, 2015).

In addition, six articles reported that some teachers held the perspective that learning can be done through play, however it was mainly endorsed as a means for furthering physical, social, and/or emotional development, rather than academic learning (Aras, 2016; Hegde et al., 2014; Howard, 2010; Lynch, 2014; Wu, 2014; Wu \& Rao, 2011). Studies that have examined German kindergarten classrooms found that teachers endorsed the use of free play without teacher intervention, pointing mainly to important social learning benefits (Wu, 2014; Wu \& Rao, 2011). One German teacher reported that children "learn a great deal in play about how to get along 
with others. They learn social behaviour" (Wu, 2014, p. 59). Similarly, a sample of teachers in Canada was found to identify on social media that the benefits of play are "social in nature" (Lynch, 2014, p. 338).

Seven studies reported a subgroup of teachers who endorsed play for academic learning, with two of these articles each mentioning only a single teacher who shared this perspective (Pui-Wah, 2008; Pyle \& Bigelow, 2015). In one qualitative study in China, three out of four interviewed teachers reported beliefs consistent with the view that learning takes place through direct instruction, with play serving as a means to capture children's initial interest and help to make them more receptive to later instruction (Pui-Wah, 2008). In contrast, one of the four teachers viewed play as an ideal pedagogy in kindergarten, where a teacher must be actively involved with children during play to facilitate learning, pointing to the endorsement of mutually directed and/or teacher-directed play (Pui-Wah, 2008). Although some studies have pointed to the view held by teachers that play can be a vehicle for developmental learning, the majority of studies have highlighted some difficulties with integrating the dichotomously viewed concepts of play and learning. This viewpoint may interfere with educational providers' abilities to facilitate a true play-based pedagogy in the classroom.

Beliefs versus practices. From the 44 articles retrieved, 22 of these spanning 10 different countries (China, South Korea, India, Guatemala, Ireland, England, Wales, Turkey, United Arab Emirates, and New Zealand) reported that despite having a recommended play-based learning curriculum in place, teachers were engaged in mainly didactic instruction (e.g., Foote et al., 2004; Hegde \& Cassidy, 2009; Li, 2004). Within this group, a further 17 articles found that the teacher participants who engaged in mainly didactic practices endorsed the concept of learning through play, highlighting a discrepancy between reported beliefs and observed practices (e.g., 
Cheng, 2001; Kim, 2004; Pui-Wah \& Stimpson, 2004). In one study conducted with six teachers in China, it was found that "although during framing before action the in-service participants emphasized the use of play for promoting social knowledge, in practice they devoted much time to routine academic work conveyed through direct instruction" (Pui-Wah \& Stimpson, 2004, p. 343). Similarly, in an examination of eight kindergarten teachers in New Zealand, Foote et al. (2004) found that "the views that teachers held about literacy as authentic, holistic and integrated in play, at times became literacy as instructional and drilled based in practice” (p. 145). Some suggested reasons for these results included underlying beliefs (that may have come from the teachers' memories of their own previous literacy learning) rather than professional knowledge impacting practice, as well as the potential influence of perceptions regarding how to meet accountability requirements (Foote et al., 2004).

In a study that interviewed 12 kindergarten teachers in India, researchers also found a gap between endorsing play-based learning and engaging in these practices, where one teacher openly commented "although we say all-around development, we stress more on the studies, so they are confused, you know" (Hedge \& Cassidy, 2009, p. 376). These researchers were unsure if the teachers' reported play-centred beliefs reflected their personal teaching philosophies or were instead the result of social desirability bias or based on their teacher training experience. Another possibility involved the teachers' recurrent use of scripted behaviours, or routine practices, centred on direct instruction in the classroom out of habit (Hedge \& Cassidy, 2009).

In contrast, one study found that four kindergarten teachers in Japan endorsed developmentally appropriate practices and the idea that learning can be done through play, emphasizing the importance of play for physical and social development in particular (Hegde et al., 2014). These teachers reported utilizing a mix of free play and teacher-directed play 
activities, reporting beliefs and practices in sync with a play-based learning pedagogy. However, no observations were conducted to compliment the teachers' interview data, and since a number of other studies found inconsistencies between report beliefs and formally observed practices, the teachers' actual practices went unknown. As one exception to the use of play-based pedagogy, parts of the United States currently emphasize academically focused curricula without a playbased focus, with one study reporting that many teachers are utilizing resistance strategies and engaging in play-based learning practices instead of following curricular recommendations (Erwin \& Delair, 2004). Although the ways in which these participants engaged in play-based learning were not discussed in depth, the authors reported that the teachers believed that "play had instructional value as well as recreational and developmental benefits" (Erwin \& Delair, 2004, p. 41). The United States was the only country discussed in the reviewed articles without a reported focus on play-based learning in the current curriculum. Although this article provides an interesting contrast, the majority of retrieved articles focused on the opposite case; namely, the use of didactic teaching rather than following a prescribed play-based learning curriculum. Furthermore, researchers have found that many teachers actually endorse the concept of learning through play, despite currently engaging in low levels of play and high levels of didactic instruction.

Implementation challenges. Another potential reason for this gap between reported beliefs and observed practices comes from reported barriers to the implementation of play-based learning in kindergarten. 30 of the retrieved articles discussed these implementation challenges, with the most commonly cited challenges including a lack of professional development or training for teachers on the subject of play-based learning (e.g., Howard, 2010; Pui-Wah \& Stimpson, 2004), pressure from parents to engage in more didactic instruction (e.g., Fung \& 
Cheng, 2012), pressure to achieve prescribed academic outcomes and prepare children for the academic demands of grade one (e.g., Baker, 2014b; Leggett \& Ford, 2013), large teacher-child ratios (e.g., Lynch, 2014; Martlew, Stephen, \& Ellis, 2011), and a lack of materials, time, and/or space in the classroom to support play (e.g., Hegde \& Cassidy, 2009; Rogers \& Evans, 2007). In a case study of one kindergarten class in China, the curriculum guidelines recommended teaching math through the use of play-based learning strategies, however the teacher reported a number of practical difficulties implementing the curriculum stemming from a lack of instructional support (Hu et al., 2014). She reported that the curriculum guide lacked details regarding the assessment of math skills as well as strategies for dealing with children having difficulties learning the designated math concepts (Hu et al., 2014). She emphasized a lack of available training and professional support to teach using these recommended play-based learning strategies and instead used mainly direct instruction (Hu et al., 2014).

With respect to parental pressure, in a case study of one kindergarten teacher in China, the participant reported beliefs in favour of play-based learning but was faced with parental requests for more academics, including more structured writing practice (Fung, 2009). The researcher noted throughout the interview that "the parents' desire to secure an early academic education for their young children prevailed as a tacit, yet powerful, intervening force impeding [the teacher's] practice of play-based pedagogy in the real setting" (Fung, 2009, p. 21). The influence of parental expectations to focus on didactic instruction over play was also discussed in studies conducted in the United Arab Emirates (Baker, 2014b), Canada (Lynch, 2014), South Korea (Kim, 2004), and India (Hegde \& Cassidy, 2009). This points to a pervasive belief in the importance of early academic teaching and a potential lack of understanding of the benefits of play in countries across the globe. 
A number of studies also pointed to pressures and concerns from teachers to get children ready for primary school, resulting in a lack of time to dedicate to play even if desired (e.g., Hegde \& Cassidy, 2009; Lynch, 2014; Wu \& Rao, 2011). In a study that examined the opinions of teachers in Ontario, Canada on social media, a commonly discussed theme was the pressure felt by kindergarten teachers to prepare children for grade one, commonly perceived as an obstacle to implementing play-based learning strategies (Lynch, 2014). One teacher commented that "as the Ontario curriculum has intensified, the academic demands can be felt as early as the kindergarten years" (Lynch, 2014, p. 340). Furthermore, early academic success is highly revered in countries such as China and South Korea in order for children to perform well on later examinations, attain social status, and bring goodwill to the family (Kim, 2004; Vong, 2012). With respect to concerns of large class sizes and a lack of resources, 12 teachers in India were interviewed and were found to endorse learning through play but lacked assistant teachers and appropriate play materials (Hegde \& Cassidy, 2009). One teacher succinctly stated, "I love play, but I need help implementing it" (Hegde \& Cassidy, 2009, p. 375). Taken together, these cultural and practical factors push teachers away from play-based strategies and towards didactic teaching practices need to be acknowledged and addressed, as they appear to be stronger than the pressure to follow the play-based curricula currently in place. Studies conducted in a number of diverse countries (e.g., China, Canada, Ireland, South Korea, United Arab Emirates, and Guatemala) reflected similar concerns from teachers, pointing to common challenges encountered on the road to effectively following play-based pedagogy in kindergarten.

\section{Summary of Research on Factors Influencing Implementation of Play}

A number of recent studies have examined current practices and teacher perspectives on play-based learning in kindergarten classrooms around the world, where several common themes 
have emerged. Firstly, many teachers have reported difficulty integrating the concepts of play and learning, instead viewing them as separate constructs and expressing some confusion with respect to how play activities can lead to learning. Secondly, some researchers have noted inconsistencies between observed classroom practices and teachers' reported beliefs, with teachers being observed to engage in mainly didactic instruction even if they have endorsed the idea that children learn best through a play-based framework. Thirdly, studies have revealed a number of reported barriers to the effective implementation of play-based learning, including a lack of professional training and pressure to engage in more didactic instruction. These three themes highlight different types of conceptual and practical barriers to the successful implementation of play-based learning pedagogy in kindergarten classrooms.

\section{Discussion}

In recent years, there has been a shift towards recommending the use of play-based pedagogies in kindergarten curricula across systems of education (e.g., Lynch, 2014; Pan \& Li, 2012; Synodi, 2010). Current research on the topic of play-based learning has commonly endorsed the use of play to foster different types of learning in this environment, both in theoretical research and in empirical research studies. These types of learning can be categorized as addressing developmental learning (such as general cognitive growth, social-emotional development, and self-regulation skills) or academic learning (including the development of math skills, oral language skills, and reading and writing skills). Both theoretical and empirical research has endorsed the use of play-based activities in kindergarten in order to foster positive development across all of these areas of learning. However, differences regarding recommended types of play and the prescribed role of the teacher have emerged. Research focused on developmental learning has consistently endorsed the use of free, or child-directed, play in order 
to foster positive learning, where teachers occupy the passive role of observer or material provider (e.g., Ghafouri \& Wien, 2005; Schwartz, 2008). Conversely, research focused on academic learning has consistently endorsed the use of teacher-directed play and mutually directed play to encourage the learning of academic skills, where teachers take an active role in play by leading play activities as well as intervening in child-led play when possible (e.g., Elvin et al., 2007; Presser et al., 2015). These two purposes (developmental/academic) are important facets of early learning, and are simultaneously addressed in current curricular mandates across a number of different countries (e.g., Ling-Yin, 2006; OME, 2011). Classroom practices need to address both areas of learning through the use of recommended play-based learning pedagogies. These observed differences between the two areas of research with respect to current recommendations and definitions of play have created an area of confusion for teachers, where different learning goals are related to different implementations of play-based learning and recommended teaching practices.

\section{Integrating Developmental and Academic Perspectives}

In the classroom, teachers are now faced with the challenge of negotiating these two contrasting recommendations from the research into classroom practices. Perspectives on how to follow the assigned curriculum, the relationship between play and learning, and the benefits of play can all impact decisions regarding the implementation of play in the classroom. With respect to beliefs regarding the assigned curriculum, teachers have been found to either take a strict curricular stance, endorsing the idea that the curriculum must be strictly followed, or an adaptive curricular stance, where more modifications and potential deviations from materials and standards are endorsed (Stevenson, 2009). Teachers that follow a strict curricular stance have reported feeling pressure to have their students meet prescribed academic standards with some 
explicitly prioritizing work over play, while teachers that follow an adaptive curricular stance have discussed valuing children having fun while they learn (Stevenson, 2009). These contrasting stances may influence teachers to interpret and utilize a play-based curriculum differently. Additionally, researchers have found that many teachers struggle with integrating the concepts of play and learning, and this has been found to be related to the teachers' use of play in the classroom (e.g., Vong, 2012; Wu, 2014). It has also been found that teachers hold differing perspectives with respect to the potential benefits of play, with some reporting that play can mainly be used to further social-emotional development (i.e., developmental learning) rather than academic learning (e.g., Hegde et al., 2014; Wu, 2014), and others reporting the perspective that academic learning can be accomplished through play-based activities (Pui-Wah, 2008; Pyle \& Bigelow, 2015). Teacher perspectives regarding the role and benefits of play (i.e., for developmental versus academic learning) have in turn been found to be related to the use of different types of play in the classroom, with teachers who endorse a developmental learning focus engaging mainly in free play, and teachers who endorse an academic learning focus tending to engage in all three types of play (teacher-directed play, mutually directed play, and free play) (Pyle \& Danniels, 2016). Contrasting perspectives on play, learning, and the curriculum have resulted in teachers tending to align themselves with one purpose or another with respect to the benefits of play (i.e., developmental or academic), which has resulted in disparate implementations and a bifurcated stance towards play in kindergarten.

Although current research has been divided with respect to the recommended implementation of play-based learning strategies, both sides have demonstrated benefits of play in early learning and development. Research focused on developmental learning in kindergarten has demonstrated connections between free play and general cognitive development, social- 
emotional development, and the development of self-regulation skills, in both theoretical and empirical examinations. Meanwhile, theoretical and empirical research focused on academic learning has accumulated evidence in favour of teacher-directed play and mutually directed play in order to support the development of math skills, literacy skills, and general subject learning. Only four of the reviewed articles focused on the benefits of play-based learning examined the use and integration of all three types of play to address early learning goals (Cutter-Mackenzie \& Edwards, 2013; Edwards \& Cutter-Mackenzie, 2011; Howard, Miles, \& Rees-Davies, 2012; Walsh et al., 2006). In order to move away from a bifurcated stance towards play and questions regarding which type of play is superior, it is proposed that questions be asked regarding the enactment of play-based learning in order to support both developmental and academic learning goals. Future research needs to help support teachers in creating a context where both goals can be integrated, since they are both important areas of child development addressed in kindergarten curricula and policy (e.g., Ling-Yin, 2006; OME, 2011).

\section{Implications}

This proposed re-conceptualization has implications for teacher practice, policy, and future research. With respect to practice, teachers need to be prepared to implement and understand play as beneficial for a variety of purposes. Current research has revealed that many teachers are struggling to integrate the concepts of play and learning (e.g., Baker, 2014a), endorse play as an important component but engage in mainly didactic instruction (e.g., Kim, 2004), and express interest in utilizing play-based learning strategies but highlight practical barriers such as a lack of training that prevents the effective use of these strategies (e.g., Pui-Wah \& Stimpson, 2004). By highlighting an integrated perspective, teachers can be shown how play is related to both positive developmental learning and academic learning, while emphasizing the importance of integrating 
multiple types of play that encompass a variety of activities and teacher roles. Play needs to be conceived as beneficial for more than one purpose in more than one form, so that educators can move away from a bifurcated stance and towards the integration of developmental and academic perspectives in the same environment.

The implementation of play in kindergarten is in part informed by policy. Future considerations include the construction of policies that are more sensitive to different approaches to play, as well as complement both developmental and academic functions. Different approaches to play require investments of time, physical space, and materials in order to engage in beneficial play-based learning activities, and constructed policies should take these factors into consideration alongside research findings that support both perspectives on play.

Through examining the current research, a lack of studies that integrate the developmental and the academic perspective have been revealed. Furthermore, direction on how educators can negotiate a balance between these recommended practices is absent. As the academic movement continues to influence kindergarten education, there is evidence of increased assessments and washback effects from upper year's large-scale assessments (Cheng, Watanabe \& Curtis, 2004). Hence, future research needs to tease apart the changing influence of an academically-driven curriculum with greater assessment pressures to understand the role of play within this evolving context. Studies are needed that work to address the integration of these two perspectives in order to support teachers to implement a balanced approach to play-based learning in kindergarten, so that children can be supported across all areas of development.

\section{Limitations}

Although this scoping review attempted to examine all relevant peer-reviewed articles on the topic of play-based learning in early years education since the shift towards mandated play- 
based learning pedagogies has taken place across a number of countries (e.g., Hunter \& Walsh, 2014; Lynch, 2014; Martlew, Stephen, \& Ellis, 2011), the use of the Education Source (EBSCOhost) database has restricted this review to articles published in education-focused journals. Therefore, some relevant articles published elsewhere may not have been retrieved and included in the current review. For example, only one empirical article was retrieved on the topic of play-based learning and the development of self-regulation skills in early years education. This may be due to a lack of articles currently published on this topic in education journals. Although it cannot be considered an exhaustive retrieval of all potentially relevant publications, this scoping review encompasses a large number of retrieved articles (168) and provides an indepth summary of much of the relevant research.

\section{Conclusion}

Internationally, kindergarten curriculums have embraced the concept of play-based learning (Synodi, 2010; Tafa, 2008). This scoping literature review has revealed a body of research in support of learning through play in kindergarten across a variety of developmental and academic learning domains. However, it has also revealed a division between these two perspectives, as well as a lack of consensus among teachers regarding the role and benefits of play in the classroom. Research focused on developmental learning has highlighted the importance of free play with a lack of teacher intervention (e.g., Hansel, 2015), while research focused on academic learning has endorsed the use of teacher-directed play and mutually directed play where the teacher instead occupies an active role (e.g., Sarama \& Clements, 2006). These differing perspectives in the research on play are reflected in research on teacher perspectives towards the role of play in learning (e.g., Pui-Wah, 2008; Wu \& Rao, 2011). Researchers and educators need to move away from a bifurcated stance and towards an 
integration of perspectives and practices, reconceptualizing the two perspectives as complementary to one another. Future policy and research need to focus on helping teachers negotiate a balance of different types of play in the classroom, in order to support the use of these empirically and theoretically endorsed play-based learning strategies. Through a process of integration and negotiation, all areas of developmental and academic learning can be supported in a play-based kindergarten. 


\section{References}

Aldhafeeri, F., Palaiologou, I., \& Folorunsho, A. (2016) Integration of digital technologies into play-based pedagogy in Kuwaiti early childhood education: Teachers' views, attitudes and aptitudes, International Journal Of Early Years Education, 24(3), 342-360.

Alvestad, M. (2011) You can learn something every day! Children talk about learning in kindergarten - traces of learning cultures, International Journal Of Early Childhood, 43(3), 291-304.

Andrews, N. (2015) Building curriculum during block play, Dimensions Of Early Childhood, 43(1), 11-15.

Aras, S. (2016) Free play in early childhood education: A phenomenological study, Early Child Development \& Care, 186(7), 1173-1184.

Arksey, H., \& O'Malley, L. (2005) Scoping studies: towards a methodological framework, International Journal of Social Research Methodology, 8(1), 19-32.

Aubrey, C., \& Durmaz, D. (2012) Policy-to-practice contexts for early childhood mathematics in England, International Journal Of Early Years Education, 20(1), 59-77.

Baker, F. S. (2014a) Teachers' views on play-based practice in Abu Dhabi kindergartens, International Journal Of Early Years Education, 22(3), 271-286.

Baker, F. S. (2014b) Tensions in policy and practice: influences on play in Abu Dhabi's new school model KG framework, Early Child Development \& Care, 184(12), 1830-1842.

Balfanz, R., Ginsburg, H. P., \& Greenes, C. (2003) The "big math for little kids" early childhood mathematics program, Teaching Children Mathematics, 9(5), 264-268.

Bers, M. U., Flannery, L., Kazakoff, E. R., \& Sullivan, A. (2014) Computational thinking and tinkering: Exploration of an early childhood robotics curriculum, Computers \& Education, 
72, 145-157.

Binder, M. (2014) The storied lives children play: Multimodal approaches using storytelling, Canadian Children, 39(2), 11-20.

Björklund, C. (2014) Powerful teaching in preschool - a study of goal-oriented activities for conceptual learning, International Journal Of Early Years Education, 22(4), 380-394.

Bodrova, E., \& Leong, D. J. (2003) Chopsticks and counting chips: Do play and foundational skills need to compete for teacher's attention in an early classroom?, Young Children, $58(3), 10-17$.

Bodrova, E., \& Leong, D. J. (2008) Developing self-regulation in kindergarten: Can we keep all the crickets in the basket?, Young Children, 63(2), 56-58.

Bottini, M., \& Grossman, S. (2005) Center-based teaching and children's learning: The effects of learning centers on young children's growth and development, Childhood Education, 81(5), 274-277.

Boyle, B., \& Charles, M. (2010) Using socio-dramatic play to support a beginning writer: 'Daniel, the doctor and the bleeding ball', International Journal Of Early Years Education, $18(3), 213-225$.

Brandt, B. (2013) Everyday pedagogical practices in mathematical play situations in German 'kindergarten', Educational Studies In Mathematics, 84(2), 227-248.

Broadhead, P. P. (2009) Conflict resolution and children's behaviour: Observing and understanding social and cooperative play in early years educational settings, Early Years, 29(2), 105-118.

Campbell, S. (2015) Feeling the pressure: Early childhood educators' reported views about learning and teaching phonics in Australian prior-to-school settings, Australian Journal Of 
Language \& Literacy, 38(1), 12-26.

Caner, M., Subaşı, G., \& Kara, S. (2010) Teachers' beliefs on foreign language teaching practices in early phases of primary education: A case study, Turkish Online Journal Of Qualitative Inquiry, 1(1), 62-76.

Casey, B. M., Andrews, N., Schindler, H., Kersh, J. E., Samper, A., \& Copley, J. (2008) The development of spatial skills through interventions involving block building activities, Cognition \& Instruction, 26(3), 269-309.

Catling, S. (2006) What do five-year-olds know of the world? - Geographical understanding and play in young children's early learning, Geography, 91(1), 55-74.

Chafel, J. A. (2003) Socially constructing concepts of self and other through play, International Journal Of Early Years Education, 11(3), 213-222.

Cheng, D. P. (2001) Difficulties of Hong Kong teachers' understanding and implementation of 'play' in the curriculum, Teaching \& Teacher Education, 17(7), 857-869.

Cheng, L., Watanabe, Y., \& Curtis, A. (2004) Washback in language testing: research contexts and methods (New Jersey, Lawrence Erlbaum \& Associates).

Chien, N. C., Howes, C., Burchinal, M., Pianta, R. C., Ritchie, S., Bryant, D. M., \& ... Barbarin, O. A. (2010) Children's classroom engagement and school readiness gains in prekindergarten, Child Development, 81(5), 1534-1549.

Cobb-Moore, C., Danby, S., \& Farrell, A. (2008) 'I told you so': Justification used in disputes in young children's interactions in an early childhood classroom, Discourse Studies, 10(5), 595-614.

Cohen, L. E. (2009) Exploring cultural heritage in a kindergarten classroom, Young Children, 64(3), 72-77. 
Cohrssen, C., Church, A., \& Tayler, C. (2014) Purposeful pauses: Teacher talk during early childhood mathematics activities, International Journal Of Early Years Education, 22(2), 169-183.

Cohrssen, C., Tayler, C., \& Cloney, D. (2015) Playing with maths: Implications for early childhood mathematics teaching from an implementation study in Melbourne, Australia, Education 3-13, 43(6), 641-652.

Colgan, L. C. (2016) Hey, it's elementary: Play and learning: The current kindergarten conundrum, Ontario Mathematics Gazette, 55(1), 20-23.

Concordia University Library (No Date). Education databases. Retrieved from https://www.concordia.ca/library/guides/education/databases.html

Cooney, M. H. (2004) Is play important? Guatemalan kindergartners' classroom experiences and their parents' and teachers' perceptions of learning through play, Journal Of Research In Childhood Education, 18(4), 261-277.

Cooper, P. M. (2005) Literacy learning and pedagogical in Vivian Paley's 'storytelling curriculum', Journal Of Early Childhood Literacy, 5(3), 229-252.

Cremin, T., Glauert, E., Craft, A., Compton, A., \& Stylianidou, F. (2015) Creative little scientists: Exploring pedagogical synergies between inquiry-based and creative approaches in Early Years science, Education 3-13, 43(4), 404-419.

Cutter-Mackenzie, A., \& Edwards, S. (2013) Toward a model for early childhood environmental education: Foregrounding, developing, and connecting knowledge through play-based learning, Journal Of Environmental Education, 44(3), 195-213.

Damian, B. (2005) Rated 5 for five-year-olds, Young Children, 60(2), 50-53.

Daniels, K. (2014) Cultural agents creating texts: a collaborative space adventure, Literacy, 
48(2), 103-111.

De La Riva, S., \& Ryan, T. G. (2015) Effect of self-regulating behaviour on young children's academic success, International Journal Of Early Childhood Special Education, 7(1), 69-96.

Doherty, A. (2012) 'Teacher, I showed her how to do that!', Primary Science, 122, 24-26.

Ebbeck, M., Yim, H., \& Lee, L. (2010) Belonging, being, and becoming: Challenges for children in transition, Diaspora, Indigenous \& Minority Education, 4(2), 103-117.

Edo, M., Planas, N., \& Badillo, E. (2009) Mathematical learning in a context of play, European Early Childhood Education Research Journal, 17(3), 325-341.

Edwards, S. (2014) Towards contemporary play: Sociocultural theory and the digitalconsumerist context, Journal Of Early Childhood Research, 12(3), 219-233.

Edwards, S., \& Cutter-Mackenzie, A. (2011) Environmentalising early childhood education curriculum through pedagogies of play, Australasian Journal Of Early Childhood, 36(1), $51-59$

Elvin, P., Maagerø, E., \& Simonsen, B. (2007) How do the dinosaurs speak in England? English in kindergarten, European Early Childhood Education Research Journal, 15(1), 71-86.

Erwin, E. J., \& Delair, H. A. (2004) Patterns of resistance and support among play-based teachers in public schools, Contemporary Issues in Early Childhood, 5(1), 35-50.

Fantuzzo, J., Sekino, Y., \& Cohen, H. L. (2004) An examination of the contributions of interactive peer play to salient classroom competencies for urban head start children, Psychology In The Schools, 41(3), 323-336.

Fisher, J. (2011) Building on the Early Years Foundation Stage: Developing good practice for transition into Key Stage 1, Early Years, 31(1), 31-42. 
Fleer, M. (2011a) 'Conceptual play': foregrounding imagination and cognition during concept formation in early years education, Contemporary Issues In Early Childhood, 12(3), 224240.

Fleer, M. (2011b) Kindergartens in cognitive times: Imagination as a dialectical relation between play and learning, International Journal Of Early Childhood, 43(3), 245-259.

Foote, L., Smith, J., \& Ellis, F. (2004) The impact of teachers' beliefs on the literacy experiences of young children: a New Zealand perspective, Early Years: Journal Of International Research \& Development, 24(2), 135-147.

Fredriksen, B. C. (2012) Providing materials and spaces for the negotiation of meaning in explorative play: Teachers' responsibilities, Education Inquiry, 3(3), 335-352.

Fung, C. K. (2009) The complexities in promoting play-based kindergarten curriculum in Hong Kong: One teacher's story, Canadian Children, 34(2), 16-24.

Fung, C. K., \& Cheng, D. P. (2012) Consensus or dissensus? Stakeholders' views on the role of play in learning, Early Years, 32(1), 17-33.

Gananathan, R. (2011) Implications of full day kindergarten program policy on early childhood pedagogy and practice, International Journal of Child Care and Education Policy, 5(2), $33-45$.

Ghafouri, F., \& Wien, C. A. (2005) “Give us a privacy”: Play and social literacy in young Children, Journal Of Research In Childhood Education, 19(4), 279-291.

Gillen, J., \& Hall, N. (2001) 'Hiya, mum!': An analysis of pretence telephone play in a nursery setting, Early Years, 21(1), 15-24.

Gmitrová, V. \& Gmitrov, J. (2004) The primacy of child-directed pretend play on cognitive competence in a mixed-age environment: Possible interpretations, Early Child 
Development \& Care, 174(3), 267-279.

Gmitrova, V., Podhajecká, M., \& Gmitrov, J. (2009) Children's play preferences: Implications for the preschool education, Early Child Development and Care, 179(3), 339-351.

Gray, C., \& Ryan, A. (2016) Aistear vis-à-vis the Primary Curriculum: The experiences of early years teachers in Ireland, International Journal Of Early Years Education, 24(2), 188-205.

Griva, E., \& Sivropoulou, R. (2009) Implementation and evaluation of an early foreign language learning project in kindergarten, Early Childhood Education Journal, 37(1), 79-87.

Gronlund, G. (2001) Rigorous academics in preschool and kindergarten? Yes! Let me tell you how, Young Children, 56(2), 42-43.

Guilfoyle, N., \& Mistry, M. (2013) How effective is role play in supporting speaking and listening for pupils with English as an additional language in the Foundation Stage?, Education 3-13, 41(1), 63-70.

Hachey, A. C., \& Butler, D. L. (2009) Seeds in the window, soil in the sensory table: Science education through gardening and nature-based play, Young Children, 64(6), 42-48.

Hadley, K. G., \& Nenga, S. K. (2004) From Snow White to Digimon: Using popular media to confront Confucian values in Taiwanese peer cultures, Childhood, 11(4), 515-536.

Hanline, M., Milton, S., \& Phelps, P. C. (2010) The relationship between preschool block play and reading and maths abilities in early elementary school: A longitudinal study of children with and without disabilities, Early Child Development \& Care, 180(8), 1005-1017.

Hansel, R. R. (2015) Bringing blocks back to the kindergarten classroom, Young Children, 70(1), 44-51.

Hard, L., \& O'Gorman, L. (2007) 'Push-me'or 'pull-you'? An opportunity for early childhood leadership in the implementation of Queensland's early years curriculum, Contemporary 
Issues in Early Childhood, 8(1), 50-60.

Harden, A. (2015) The discourse of drama supporting literacy learning in an early years classroom, Australian Journal Of Language \& Literacy, 38(3), 141-149.

Harden, A. (2016) 'Caterpillars and catalysts': A year of literacy learning in an early years classroom privileging dramatic pedagogies, Australasian Journal Of Early Childhood, 41(3), 20-28.

Hayes, R. (2005) Conversation, negotiation, and the word as deed: Linguistic interaction in a dual language program, Linguistics \& Education, 16(1), 93-112.

Hegde, A. V., \& Cassidy, D. J. (2009) Kindergarten teachers' perspectives on developmentally appropriate practices (DAP): A study conducted in Mumbai (India), Journal Of Research In Childhood Education, 23(3), 367-381.

Hegde, A. V., Sugita, C., Crane-Mitchell, L., \& Averett, P. (2014) Japanese nursery and kindergarten teachers' beliefs and practices regarding developmentally appropriate practices, International Journal Of Early Years Education, 22(3), 301-314.

Henry, M. (1990) More than just play: The significance of mutually directed adult-child activity, Early Child Development and Care, 60(1), 35-51.

Hood, P. (2013) The development of high-quality interaction and thinking alongside the extension of child-initiated learning into key stage one: A whole school initiative, Early Child Development \& Care, 183(8), 1181-1196.

Hope-Southcott, L. (2013) The use of play and inquiry in a kindergarten drama centre: A teacher's critical reflection, Canadian Children, 38(1), 39-46.

Howard, J. (2010) Early years practitioners' perceptions of play: An exploration of theoretical understanding, planning and involvement, confidence and barriers to practice, Educational 
\& Child Psychology, 27(4), 91-102.

Howard, J., Miles, G. E., \& Rees-Davies, L. (2012) Computer use within a play-based early years curriculum, International Journal Of Early Years Education, 20(2), 175-189.

Howes, C. H., Wishard Guerra, A., Fuligni, A., Zucker, E., Lee, L., Obregon, N. B., \& Spivak, A. (2011) Classroom dimensions predict early peer interaction when children are diverse in ethnicity, race, and home language, Early Childhood Research Quarterly, 26(4), 399-408.

Hoyte, F., Torr, J., \& Degotardi, S. (2015) Creating pretence and sharing friendship: modal expressions in children's play, International Journal Of Early Years Education, 23(1), 1730.

Hu, B. H., Fuentes, S. Q., Wang, C. Y., \& Ye, F. (2014) A case study of the implementation of Chinese kindergarten mathematics curriculum, International Journal Of Science \& Mathematics Education, 12(1), 193-217.

Hunter, T., \& Walsh, G. (2014) From policy to practice?: The reality of play in primary school classes in Northern Ireland, International Journal Of Early Years Education, 22(1), 19-36.

Ihmeideh, F. (2015) The impact of dramatic play centre on promoting the development of children's early writing skills, European Early Childhood Education Research Journal, 23(2), 250-263.

Isom, C. (2014) A picture is worth a thousand words: A kindergarten illustration study, English In Texas, 44(1), 42-46.

James, K., Bearne, E., \& Alexander, E. (2004) 'Doggy's dead': Reflecting on a teacher research study about young children's sociodramatic play, Teacher Development, 8(2/3), 165-180.

Jarvis, S. (2013) How effective is it to teach a foreign language in the Foundation Stage through songs and rhymes?, Education 3-13, 41(1), 47-54. 
Kamii, C. (2003) Modifying a board game to foster kindergartners' logico-mathematical Thinking, Young Children, 58(5), 20-26.

Kim, H., Park, E., \& Lee, J. (2001) “All done! Take it home.” Then into a Trashcan?: Displaying and using children's art projects, Early Childhood Education Journal, 29(1), 41-50.

Kim, M. (2004) Teachers' philosophical orientation and practices: a study of novice preschool teachers in South Korea, Contemporary Issues in Early Childhood, 5(3), 276-292.

Korat, O., Bahar, E., \& Snapir, M. (2002) Sociodramatic play as opportunity for literacy development: The teacher's role, Reading Teacher, 56(4), 386-393.

Kotsopoulos, D., Makosz, S., Zambrzycka, J., \& McCarthy, K. (2015) The effects of different pedagogical approaches on the learning of length measurement in kindergarten, Early Childhood Education Journal, 43(6), 531-539.

Lee, S., \& Goh, G. (2012) The author(s) 2012 action research to address the transition from kindergarten to primary school: Children's authentic learning, construction play, and pretend play, Early Childhood Research \& Practice, 14(1), 1-16.

Leggett, N., \& Ford, M. (2013) A fine balance: Understanding the roles educators and children play as intentional teachers and intentional learners within the Early Years Learning Framework, Australasian Journal Of Early Childhood, 38(4), 42-50.

Leseman, P. M., Rollenberg, L., \& Rispens, J. (2001) Playing and working in kindergarten: Cognitive co-construction in two educational situations, Early Childhood Research Quarterly, 16(3), 363-384.

Li, Y. L. (2004) The culture of teaching in the midst of western influence: The case of Hong Kong kindergartens, Contemporary Issues in Early Childhood, 5(3), 330-348.

Lim, E. (2012) Patterns of kindergarten children's social interaction with peers in the computer 
area, International Journal Of Computer-Supported Collaborative Learning, 7(3), $399-421$.

Ling-Yin, L. A. (2006) Steering debate and initiating dialogue: A review of the Singapore preschool curriculum, Contemporary Issues in Early Childhood, 7(3), 203-212.

Liu, E. Z., Lin, C., Liou, P., Feng, H., \& Hou, H. (2013) An analysis of teacher-student Interaction patterns in a robotics course for kindergarten children: A pilot study, TOJET: The Turkish Online Journal of Educational Technology, 12(1), 9-18.

Liu, M. H., Karp, G. G., \& Davis, D. (2010) Teaching learning-related social skills in kindergarten physical education, The Journal Of Physical Education, Recreation \& Dance, 81(6), 38-44.

Lynch, M. (2014) Ontario kindergarten teachers' social media discussion about full day Kindergarten, McGill Journal of Education, 49(2), 329-347.

Lynch, M. (2015) Guys and dolls: A qualitative study of teachers' views of gendered play in kindergarten, Early Child Development \& Care, 185(5), 679-693.

Lysaker, J., Wheat, J., \& Benson, E. (2010) Children's spontaneous play in writer's workshop, Journal Of Early Childhood Literacy, 10(2), 209-229.

Maher, M., \& Smith, S. (2014) Asylum seeker and refugee children belonging, being and becoming: The early childhood educator's role, Australasian Journal Of Early Childhood, 39(1), 22-29.

Martlew, J., Ellis, S., Stephen, C., \& Ellis, J. (2010) Teacher and child talk in active learning and whole-class contexts: Some implications for children from economically less advantaged home backgrounds, Literacy, 44(1), 12-19.

Martlew, J., Stephen, C., \& Ellis, J. (2011) Play in the primary school classroom? The 
experience of teachers supporting children's learning through a new pedagogy, Early Years, 31(1), 71-83.

Matthews, J. (2006) Presentation, representation and e-presentation in early childhood. International Journal Of Education Through Art, 2(3), 171-182.

Maynard, T., \& Chicken, S. (2010) Through a different lens: Exploring Reggio Emilia in a Welsh context, Early Years, 30(1), 29-39.

McGuinness, C., Sproule, L., Bojke, C., Trew, K., \& Walsh, G. (2014) Impact of a play-based curriculum in the first two years of primary school: Literacy and numeracy outcomes over seven years, British Educational Research Journal, 40(5), 772-795.

McInnes, K., Howard, J. J., Miles, G. E., \& Crowley, K. (2009) Behavioural differences exhibited by children when practising a task under formal and playful conditions, Educational \& Child Psychology, 26(2), 31-39.

McInnes, K., Howard, J. J., Miles, G. E., \& Crowley, K. (2010) Differences in adult-child interactions during playful and formal practice conditions: An initial investigation, Psychology Of Education Review, 34(1), 14-20.

McInnes, K., Howard, J. J., Miles, G. E., \& Crowley, K. (2011) Differences in practitioners' understanding of play and how this influences pedagogy and children's perceptions of play, Early Years, 31(2), 121-133.

McLennan, D. P. (2012) Classroom bird feeding, Young Children, 67(5), 90-93.

McNamee, G. D. (2005) 'The one who gathers children': The work of Vivian Gussin Paley and current debates about how we educate young children, Journal Of Early Childhood Teacher Education, 25(3), 275-296.

Miller, D., Robertson, D., Hudson, A., \& Shimi, J. (2012) Signature pedagogy in early years 
education: A role for COTS game-based learning, Computers In The Schools, 29(1/2), 227247.

Miller, L., \& Smith, A. P. (2004) Practitioners' beliefs and children's experiences of literacy in four early years settings, Early Years, 24(2), 121-133.

Miller, S. A. (2005) Reflections on kindergarten: Giving young children what they deserve, Childhood Education, 81(5), 256-260.

Moon, K., \& Reifel, S. (2008) Play and literacy learning in a diverse language pre-kindergarten classroom, Contemporary Issues In Early Childhood, 9(1), 49-65.

Moore, H. C., \& Adair, J. K. (2015) “I’m just playing iPad": Comparing prekindergarteners' and preservice teachers' social interactions while using tablets for learning, Journal Of Early Childhood Teacher Education, 36(4), 362-378.

Newbury, K., Wooldridge, D., Peet, S., \& Bertelsen, C. (2015) From policy to practice: Laying the foundation for future math success, Delta Kappa Gamma Bulletin, 81(4), 8-17.

Ng, S., \& Rao, N. (2008) Mathematics teaching during the early years in Hong Kong: A reflection of constructivism with Chinese characteristics?, Early Years, 28(2), 159-172.

Nicolopoulou, A. (2010) The alarming disappearance of play from early childhood education, Human Development, 53(1), 1-4.

Nikolopoulou, K., \& Gialamas, V. (2015) ICT and play in preschool: Early childhood teachers' beliefs and confidence, International Journal Of Early Years Education, 23(4), 409-425.

Nordtømme, S. (2012) Place, space and materiality for pedagogy in a kindergarten, Education Inquiry, 3(3), 317-333.

Ontario Ministry of Education (2011) The full-day early learning — kindergarten program. Available online at: 
http://www.edu.gov.on.ca/eng/curriculum/elementary/kindergarten_english_june3.pdf (accessed 19 October 2016).

Palaiologou, I. (2016) Teachers' dispositions towards the role of digital devices in play-based pedagogy in early childhood education, Early Years, 36(3), 305-321.

Pan, Y. J., \& Li, X. (2012) Kindergarten curriculum reform in mainland China and reflections, in: J. A. Sutterby (Ed) Advances in early education and day care. Vol. Sixteen: Early education in a global context (Emerald Group Publishing Limited).

Piker, R. A. (2013) Understanding influences of play on second language learning: A microethnographic view in one Head Start preschool classroom, Journal Of Early Childhood Research, 11(2), 184-200.

Pinto, L. E. (2016) “Collect 'em all”: Gender, consumerism and the Shopkins phenomenon, Our Schools / Our Selves, 25(2), 11-14.

Poland, M., \& van Oers, B. (2007) Effects of schematising on mathematical development, European Early Childhood Education Research Journal, 15(2), 269-293.

Pramling Samuelsson, I. \& Johansson, E. (2006) Play and learning_-inseparable dimensions in preschool practice, Early Child Development and Care, 176(1), 47-65.

Presser, A. L., Clements, M., Ginsburg, H., \& Ertle, B. (2015) Big math for little kids: The effectiveness of a preschool and kindergarten mathematics curriculum, Early Education \& Development, 26(3), 399-426.

Pyle, A. \& Bigelow, A. (2015) Play in kindergarten: An interview and observational study in three Canadian classrooms, Early Childhood Education Journal, 43(5), 385-393.

Pyle, A., \& Danniels, E. (2016) A continuum of play-based learning: The role of the teacher in a play-based pedagogy and the fear of hijacking play, Early Education \& Development doi: 
$10.1080 / 10409289.2016 .1220771$

Pui-Wah, D. C. (2008) Meta-learning ability - a crucial component for the professional development of teachers in a changing context, Teacher Development, 12(1), 85-95.

Pui-Wah, D. C., \& Stimpson, P. (2004) Articulating contrasts in kindergarten teachers' implicit knowledge on play-based learning, International Journal Of Educational Research, 41, 339-352.

Regush, N., Anderson, J., \& Lee, E. A. (2002) Using play as a context for children's acquisition of phonemic awareness, Yearbook Of The College Reading Association, 234-246.

Rhoades, M. (2016) 'Little pig, little pig, let me come in!' Animating the three little pigs with preschoolers, Early Childhood Education Journal, 44(6), 595-603.

Riek, J. (2014) Reinstating P.L.A.Y. pedagogy in early elementary classrooms, International Journal Of Early Childhood Learning, 22(1), 1-10.

Roberts-Holmes, G. (2012) 'It's the bread and butter of our practice': Experiencing the Early Years Foundation Stage, International Journal Of Early Years Education, 20(1), 30-42.

Rogers, S., \& Evans, J. (2007) Rethinking role play in the Reception class, Educational Research, 49(2), 153-167.

Rothman, J. (2006) Life lessons: Story acting in kindergarten, Young Children, 61(5), 70-76.

Samuelsson, I., \& Carlsson, M. A. (2008) The playing learning child: Towards a pedagogy of early childhood, Scandinavian Journal Of Educational Research, 52(6), 623-641.

Saracho, O. N. (2002) Teachers' roles in promoting literacy in the context of play, Early Child Development \& Care, 172(1), 23-34.

Sarama, J., \& Clements, D. H. (2006) Mathematics in kindergarten, Young Children, 61(5), 
$38-41$.

Schwartz, E. (2008) From playing to thinking: How the kindergarten provides a foundation for scientific understanding, European Journal Of Psychotherapy \& Counselling, 10(2), $137-145$.

Shanker, S. (2010) Self-regulation: Calm, alert and learning, Education Canada, 50(3), 105-138.

Sharp, A. C., Escalante, D. L., \& Anderson, G. T. (2012) Literacy instruction in kindergarten: Using the power of dramatic play, California English, 18(2), 16-18.

Siraj-Blatchford, I. (2009) Conceptualising progression in the pedagogy of play and sustained shared thinking in early childhood education: A Vygotskian perspective, Educational \& Child Psychology, 26(2), 77-89.

Siraj-Blatchford, I., \& Sylva, K. (2004) Researching pedagogy in English pre-schools, British Educational Research Journal, 30(5), 713-730.

Stephen, C. (2010) Pedagogy: The silent partner in early years learning, Early Years, 30(1), 1528.

Stephen, C., \& Plowman, L. (2003) Information and communication technologies in pre-school settings: A review of the literature, International Journal Of Early Years Education, $11(3), 223-234$.

Stoll, J., Hamilton, A., Oxley, E., Eastman, A. M., \& Brent, R. (2012) Young thinkers in motion, Young Children, 67(2), 20-26.

Sylva, K. K., Taggart, B., Siraj-Blatchford, I., Totsika, V., Ereky-Stevens, K., Gilden, R., \& Bell, D. (2007) Curricular quality and day-to-day learning activities in pre-school, International Journal Of Early Years Education, 15(1), 49-65.

Synodi, E. (2010) Play in the kindergarten: The case of Norway, Sweden, New Zealand and 
Japan, International Journal Of Early Years Education, 18(3), 185-200.

Tafa, E. (2008) Kindergarten reading and writing curricula in the European Union, Literacy, 42(3), 162-170.

Tal, C., Fares, E., Azmi, R., \& Waab, W. (2008) Beyond learning and teaching in preschool free-play centers in Daliat el-Carmel-Isfiya, Early Childhood Education Journal, 36(3), 281-289.

van der Graaf, J., Segers, E., \& Verhoeven, L. (2016) Discovering the laws of physics with a serious game in kindergarten, Computers \& Education, 101, 168-178.

Vangsnes, V., Gram Økland, N. T., \& Krumsvik, R. (2012) Computer games in pre-school settings: Didactical challenges when commercial educational computer games are implemented in kindergartens, Computers \& Education, 58(4), 1138-1148.

Van Oers, B., \& Duijkers, D. (2013) Teaching in a play-based curriculum: Theory, practice and evidence of developmental education for young children, Journal Of Curriculum Studies, 45(4), 511-534.

Veraksa, A., \& Veraksa, N. (2016) Symbolic representation in early years learning: The acquisition of complex notions, European Early Childhood Education Research Journal, 24(5), 668-683.

Vollrath, M. M. (2007) Play as process: Choice, translation, reconfiguration, and the process of culture, Visual Arts Research, 33, 63-70.

Vong, K. (2012) Play - a multi-modal manifestation in kindergarten education in China, Early Years, 32(1), 35-48.

Vriens-van Hoogdalem, A., de Haan, D. M. P., \& Boom, J. (2016) The role of language ability in young children's cooperation during play and collaborative interactions, Early Child 
Development \& Care, 186(9), 1491-1504.

Vu, J. A., Han, M., \& Buell, M. J. (2015) The effects of in-service training on teachers' beliefs and practices in children's play, European Early Childhood Education Research Journal, 23(4), 444-460.

Wallerstedt, C. \& Pramling, N. (2012) Learning to play in a goal-directed practice, Early Years, 32(1), 5-15.

Walsh, G., \& Gardner, J. (2006) Teachers' readiness to embrace change in the early years of schooling: A Northern Ireland perspective, European Early Childhood Education Research Journal, 14(2), 127-140.

Walsh, G., McGuinness, C., Sproule, L., \& Trew, K. (2010) Implementing a play-based and developmentally appropriate curriculum in Northern Ireland primary schools: What lessons have we learned?, Early Years, 30(1), 53-66.

Walsh, G., Sproule, L., McGuinness, C., \& Trew, K. (2011) Playful structure: A novel image of early years pedagogy for primary school classrooms, Early Years, 31(2), 107-119.

Walsh, G., Sproule, L., McGuinness, C., Trew, K., Rafferty, H., \& Sheehy, N. (2006) An appropriate curriculum for 4-5-year-old children in Northern Ireland: Comparing playbased and formal approaches, Early Years, 26(2), 201-221.

Wang, A. H., Shen, F., \& Byrnes, J. P. (2013) Does the opportunity-propensity framework predict the early mathematics skills of low-income pre-kindergarten children?, Contemporary Educational Psychology, 38(3), 259-270.

Wang, Z., \& Hung, L. M. (2010) Kindergarten children's number sense development through board games, International Journal Of Learning, 17(8), 19-31.

Warner, M. (2009) Out of an old toy chest, Journal Of Aesthetic Education, 43(2), 3-18. 
Weisberg, D. S., Hirsh-Pasek, K., \& Golinkoff, R. M. (2013) Guided play: Where curricular goals meet a playful pedagogy, Mind, Brain, and Education, 7(2), 104-112.

Whaley, C. (2002) Meeting the diverse needs of children through storytelling, Young Children, $57(2), 31-34$.

Whitburn, J. (2003) Learning to live together: The Japanese model of early years education, International Journal Of Early Years Education, 11(2), 155-175.

Winston, J. (2013) "Play is the thing!": Shakespeare, language play and drama pedagogy in the early years, Journal Of Aesthetic Education, 47(2), 1-15.

Wohlwend, K. (2008) Play as a literacy of possibilities: Expanding meanings in practices, materials, and spaces, Language Arts, 86(2), 127-136.

Wood, E. A. (2014) Free choice and free play in early childhood education: Troubling the discourse, International Journal Of Early Years Education, 22(1), 4-18.

Wood, E., \& Attfield, J. (2005) Play, learning and the early childhood curriculum (London, PCP Limited).

Wood, L. D. (2014) Holding on to play: Reflecting on experiences as a playful K-3 teacher, Young Children, 69(2), 48-56.

Woodard, C., Haskins, G., \& Schaefer, G. (2004) Let's talk: A different approach to oral language development, Young Children, 59(4), 92-95.

Wu, S. (2014) Practical and conceptual aspects of children's play in Hong Kong and German Kindergartens, Early Years, 34(1), 49-66.

Wu, S., \& Rao, N. (2011) Chinese and German teachers' conceptions of play and learning and children's play behavior, European Early Childhood Education Research Journal, 19(4), 469-481. 
Yoon, H. S. (2014) Can I play with you? The intersection of play and writing in a kindergarten Classroom, Contemporary Issues In Early Childhood, 15(2), 109-121.

Young, J. (2009) Enhancing emergent literacy potential for young children, Australian Journal Of Language \& Literacy, 32(2), 163-180.

Table 1

Scoping Review Search Results

\begin{tabular}{|l|l|l|l|}
\hline Database & Search terms & Limiters & Search results \\
Education Source & Play-based learning AND & Scholarly (peer-reviewed) journals; & 36 \\
\hline Education Source & Playful learning AND & Scholarly (peer-reviewed) journals; & 12 \\
(EBSCOhost) & kindergarten OR early years & Published date: 2000 - 2016 & \\
\hline Education Source & Inquiry AND play AND & Scholarly (peer-reviewed) journals; & 31 \\
(EBSCOhost) & kindergarten OR early years & Published date: 2000 - 2016 & 105 \\
\hline Education Source & Play based AND & Scholarly (peer-reviewed) journals; & 16 \\
(EBSCOhost) & kindergarten OR early years & Published date: 2000 - 2016 & \\
\hline
\end{tabular}




\begin{tabular}{|l|l|l|l|}
\hline Education Source & Play AND learning AND & Scholarly (peer-reviewed) journals; & 459 \\
(EBSCOhost) & kindergarten OR early years & Published date: 2000 - 2016 & \\
\hline
\end{tabular}

